\title{
Vida y MUerte en el Perú colonial: inicios de la bioARQUeología EN LAMBAYEQUe histórico (I 536 -I 750 D.C.)
}

\author{
Haagen D. Klaus ${ }^{\text {a }}$
}

\begin{abstract}
Resumen
Considerando la totalidad de los desarrollos y dinámicas culturales que abarca la historia andina, el contacto entre los andinos y los europeos a partir del siglo XVI no tiene precedentes en términos de su alcance, impacto y violencia. Paradójicamente, es la época que ha recibido poca atención arqueológica. El Perú histórico, casi siempre, ha sido estudiado a través de las fuentes etnohistóricas que son reveladoras e incompletas, a menudo distorsionadas por capas de etnocentrismo europeo y percepción errónea del comportamiento de las culturas andinas. A menudo, la vida misma y los matices de las experiencias vividas por las culturas nativas son desconocidos, y están cubiertos de misterio y de una amplia gama de supuestos acerca de la sociedad colonial que surgió de la estela de la conquista. En este articulo, se aplican las perspectivas bioarqueológicas en el estudio de los Andes Centrales coloniales. Las excavaciones en el pueblo de Mórrope, valle de Lambayeque (Costa Norte del Perü), nos permiten integrar múltiples lineas de datos independientes etnohistóricos, arqueológicos y biológicos para examinar dos cuestiones centrales: 1) ¿Cómo impactó la conquista en los patrones de salud, actividad fisica y dieta prehispánicos? 2) ¿Qué revelan los patrones de enterramiento como experiencias paralelas de cambio cultural e identidad nativa en el Perú colonial?
\end{abstract}

Palabras clave: Mórrope (Lambayeque, Perú), bioarqueología, salud prehispánica, cambio cultural e identidad

\section{Abstract \\ LIFE AND DEATH IN COLONIAL PERU: THE BEGINNINGS OF BIOARCHAEOLOGY IN HISTORICAL LAMBAYEQUE (1536-1750 d.C.)}

Considering all the developments and dynamics spanning the Andean cultural history, contact between Andeans and Europeans in the sixteenth century was unprecedented in terms of scope, impact and violence. Paradoxically, it is a time period that has received little archaeological attention. Historic Peru has almost always been studied through the ethnohistorical sources, revealing incomplete and often distorted by layers of European ethnocentrism and behavioral misperception of Andean cultures. Often, the very lives of people and the nuanced experiences of native cultures have remained unknown, obscured by a lack of data and wide range of assumptions about the colonial society that emerged in the wake of the conquest. This article applies bioarchaeological perspectives in the study of colonial Central Andes. The excavations in the village of Mórrope, Lambayeque Valley (northern Peru) allows us to integrate multiple independent lines of ethnohistoric, archaeological, and biological data to examine two central issues: (1) How did conquest impact patterns of pre-Hispanic health, diet, and physical activity? (2) What do burial patterns reveal about parallel processes of native cultural change and identity in colonial Peru?

Keywords: Mórrope (Lambayeque, Perui), bioarchaeology, pre-Hispanic health, cultural change and identity

a Departamento de Antropología, George Mason University

Museo Nacional de Sicán

Correo electrónico: hklaus@gmu.edu 


\section{Sobre contextos bioculturales: Una introducción}

En Antropología, el tema del contacto en las Américas recibió una renovada atención al conmemorarse los quinientos ańos de su descubrimiento y con el surgimiento de la ciencia bioarqueológica, que interpreta los patrones de comportamiento y la cultura a través del estudio de la biología humana ósea y dental (Larsen 2015). Muchos supuestos convincentes acerca de la universalidad de la caída demográfica indígena, la aniquilación inevitable de las sociedades indígenas y la declinación natural monolítica, han sido puestos en duda por estudios bioarqueológicos de restos humanos de América del Norte y Central. Estas investigaciones revelan que, si bien tanto la despoblación indígena como el aumento de la morbilidad fueron causados frecuentemente por el contacto, el tiempo y modo en que sucedieron estos fenómenos fueron muy diversos, como las ambiciones económicas de los europeos, los patrones de salud previos al momento de contacto, las enfermedades, la complejidad social, la estructura de la población, la ecología, las adaptaciones culturales locales y los ajustes europeos (Verano y Ubelaker 1992; Larsen y Milner 1994; Baker y Kealhoffer 1996). En América del Sur, solo un estudio «poscontacto» ha surgido de los Andes del norte de Ecuador (Ubelaker y Newson, 2002). La historia bioarqueológica del Perú colonial y su gente prácticamente no ha sido escrita.

Otra vía clave para explorar la transición poscontacto en el Perú, e inseparable del estudio bioarqueológico, es el ritual funerario. Los rituales funerarios tienden a ser un «fenómeno social total», o la integración plena de las condiciones sociales, políticas, económicas e ideológicas dentro de una sociedad compleja (Beck 1995). Los comportamientos funerarios históricos del Nuevo Mundo nativo permanecen poco estudiados. Sin embargo, el estudio de los patrones de enterramiento es un terreno especialmente fértil dado el grado en que el tratamiento de los muertos fue de dominio cultural en el Perú colonial (Ramos 2010).

En otras partes de las Américas, los patrones funerarios poscontacto ilustran evidentes transformaciones ideológicas de los pueblos indígenas enterrados al estilo cristiano en las iglesias de la Florida Española, México y Belice (Cohen et al. 1997; Larsen 2001; Tiesler et al. 2010). Los primeros pasos en la arqueología funeraria del Perú poscontacto se llevan a cabo con las investigaciones de Wernke (2007a, 2007b, 2010) en Malata (época Colonial Temprana, valle del Colca), donde se halla evidencias tanto materiales como en la disposición de los cuerpos en un escenario de tensiones dialécticas, resultado de prácticas sociales y religiosas euroandinas híbridas, en las que persiste la cultura indígena. Las excavaciones de Magdalena de Cao Viejo (Complejo El Brujo, valle de Chicama) por Quilter $(2007,2010)$, descubrieron cerca de 30 entierros que evidencian la adhesión de los fieles al ritual funerario europeo sin hibridación alguna. Sin embargo, los rituales domésticos en las casas del pueblo colonial encarnan un sincretismo y resistencia ritualizada en mayor medida. En la costa central fuera de Lima, Murphy et al. (2010a) identifican el desglose y la reconfiguración de las prácticas funerarias tradicionales en Puruchuco-Huaquerones. Aquí, durante las primeras décadas de la Colonia, suceden significativos trastornos caracterizados por episodios de extrema violencia (Murphy et al. 2010b), pero también de conflicto ritual, bien ilustrado por el entierro de una mujer probablemente hallada en un cementerio asociado a la iglesia temprana, y que habría sido exhumada de manera clandestina y reenterrada en el cementerio indígena.

El árido valle de Lambayeque, al norte del Perú, es una de las regiones en donde la historia colonial ha sido particularmente descuidada. Los desarrollos prehispánicos en esta región, sin embargo, han sido bien estudiados en los últimos tres decenios, y es claro que Lambayeque fue un importante centro de influyentes y poderosas culturas prehispánicas, al menos desde el año 1500 a.C., como es el caso de las sociedades Cupisnique, Moche y Sicán (o Lambayeque) (Shimada 1995, 1994; Elera 1997; Alva 2008). Estudios de entierros bien documentados de la región (principalmente, por el Proyecto Arqueológico Sicán y varios proyectos del Museo Brüning) han caracterizado la salud, la organización social, los rituales funerarios y la ideología especialmente por el centi de cultura regional prehispánica (la cultura Sicán Medio o Lambayeque Clásico, 900-1100 d.C.) (Shimada et al. 2004; Klaus 2014; Klaus et al. 2014). 
Esto nos lleva a comprender que gran parte de la población regional prehispánica tardía fue descendiente de la cultura Moche (100-750 d.C.), grupo distintivo étnico muchik que persistió hasta el contacto con otras culturas (Klaus 2008, 2014). Muchas señales de codificación, simbolismo e identidad étnica muchik se observan en la gramática muy conservadora de su patrón funerario, en la que los individuos están alineados con un punto cardinal (por lo general, a lo largo del eje norte-sur) y acompañados por algunas piezas de hasta cinco tipos de ofrendas distintas, como botellas de cerámica, artículos de cobre o bronce colocado en las manos o la boca, y ofrendas de camélidos. La manipulación intencional de restos humanos (especialmente cráneos y huesos largos), correspondientes en gran parte al grupo étnico muchik, ha sido recientemente documentada en una serie de tumbas, cementerios y sacrificios humanos en la región Lambayeque, que abarca también los períodos Sicán, Chimú e Inca.

Con la invasión española en 1532, se inician cambios irrevocables y profundos en los Andes Centrales. Como la Costa Norte del Perú carecía de un cronista dedicado, la incompleta etnohistoria colonial de Lambayeque ha sido construida a partir de los fragmentos de una variedad de fuentes históricas, documentos legales, registros municipales y otros informes. En particular, Ramírez (1996) identifica una serie de referencias sobre los esfuerzos españoles para controlar y transformar la cultura indígena. Hacia la década de 1590, se produjo una ruptura total con el pasado prehispánico. Los colonos ibéricos trataron de transformar el terreno de Lambayeque en vastas plantaciones, haciendas semiindustriales y de extracción de recursos minerales, utilizando a los muchik como mano de obra. Las comunidades muchik, tal y como en 1540, fueron trasladadas por la fuerza de los pueblos coloniales (reducciones) a densos asentamientos nucleados, donde se podía manipular su trabajo con el cobro de impuestos. Otras fuentes (Heyerdahl et al. 1996), describen episodios de violenta persecución religiosa. Las comunidades se sumieron en la pobreza y los sistemas de bienestar colectivo se desintegraron (Ramírez 1996). Un manuscrito incompleto de 1782, escrito por el sacerdote Rubiños y Andrade (1936 [1782]), se centró en la historia colonial del pequeño pueblo muchik de Mórrope. Él describe las experiencias indígenas de marginación socioeconómica, manipulación, violencia y otras atrocidades que contribuyeron a lo que estudiosos como John Bodley (1999) consideran un contexto de etnocidio.

\section{Hipótesis de investigación}

En este sombrío contexto de negativas transformaciones bioculturales tras la conquista de Lambayeque, este trabajo pone a prueba dos hipótesis simples, pero vinculadas. Primero, en comparación con los últimos años de su población prehispánica, los pueblos coloniales de Lambayeque tuvieron mayores índices de enfermedades, morbilidad y estrés biológico. Segundo, en condiciones tan evidentes de persecución religiosa y estrés cultural, las prácticas mortuorias prehispánicas fueron eliminadas y reemplazadas por costumbres católicas europeas.

\section{Materiales y métodos}

\subsection{El contexto arqueológico}

Unos de los primeros lugares en donde el cristianismo se estableció en el valle de Lambayeque fue el pequeño pueblo muchik de Mórrope, ubicado en el kilómetro 802 de la carretera Panamericana Norte y que limita por el norte con el desierto de Sechura (Fig. 1). Existe evidencia de una continua ocupación local que se remonta al menos a Moche V (550-750 d.C.). Mórrope se encuentra en un microambiente de matorral (monte) y la abundancia de arcillas lo ha llevado a una especialización artesanal a nivel comunitario, con uso de tecnologías prehispánicas como el paleteado para la fabricación de cerámica (Cleland y Shimada 1998). La Capilla de San Pedro de Mórrope se estableció en junio de 1536 y fue abandonada en algún momento entre 1720 y 1751. Los trabajos de restauración y estudio arqueológico se iniciaron en 2003 (Fig. 2). En 10 meses de excavaciones 
de gran escala y análisis de laboratorio desde 2004, se documentaron diferentes actividades, las fases de construcción y los patrones funerarios en la Capilla (Klaus 2008; Klaus 2013, 2014; Klaus y Tam 2009a, 2009b, 2014; Klaus et al. 2009; Klaus et al. 2010) (Fig. 3).

\section{Midiendo la vida y la muerte}

\subsection{El estrés sistémico}

Este se define como cualquier perturbación que altera el equilibrio fisiológico de un individuo (Huss-Ashmore et al. 1982). Este concepto involucra la interacción entre los agentes patógenos, nutrientes, economía, medioambiente y las estructuras sociales que alteran la homeostasis biológica en formas empíricamente observables. Para probar las hipótesis, se manejaron variables óseas que reflejan la interrupción de la homeostasis metabólica e inmunológica, y que fueron examinadas en tres subadultos y dos adultos.

En primer lugar, se encuentran las hipoplasias lineales del esmalte (HLE), que son bandas de menor grosor del esmalte que proporcionan un indicador casi indeleble de estrés durante la formación de la corona del diente, y que abarca la infancia y la niñez (Fig. 4, superior). Estos defectos se asocian a las formas agudas de estrés a partir de infección, nutrición inadecuada y diarrea al momento del destete (Goodman y Rose 1990). Las HLE son observables macroscópicamente y bajo una lupa de mano de diez aumentos, lo que ayuda a definir las variaciones normales de los perikymata y la hipoplasia del esmalte. Los defectos examinados aquí corresponden a dientes anteriores antimeros (incisivos superiores e inferiores y caninos), que ayudan a descartar el diagnóstico diferencial de un traumatismo localizado o defectos hereditarios.

En segundo lugar, la hiperostosis porótica es un síndrome morfológico que resulta de la hiperactividad de los espacios hematopoyéticos de la médula roja en el cráneo durante la infancia, y está vinculada a la anemia crónica en la mayoría de las poblaciones arqueológicas, más probablemente con una anemia de tipo megaloblástica o hemolítica, y las deficiencias crónicas de la vitamina B12 y B9 (Walker et al. 2009). Las lesiones esponjosas características se manifiestan principalmente en la bóveda craneal posterior (Fig. 4, inferior).

En tercer lugar, el crecimiento refleja la unión de los entornos sociales, económicos y políticos con el estado nutricional de los nińos (Bogin 2001). La reducción del crecimiento está estrechamente relacionada con la nutrición insuficiente, las infecciones y el gasto energético elevado que conduce a la insuficiencia de suministro de nutrientes a nivel celular (Bogin 1999; Martorell 1989). El crecimiento humano se expresa en una curva de dos componentes, que a su vez, presentan distintos componentes prepúberes y adolescentes. Para estimar la curva de crecimiento prepuberal, se midió la máxima longitud femoral izquierda de la diáfisis en 35 niños prehispánicos y 58 niños poscontacto. Los individuos de entre 0 a 12 años fueron medidos usando un tablero osteométrico con una precisión de $0,10 \mathrm{~mm}$. Las curvas de crecimiento se calcularon utilizando un análisis de regresión no lineal de la longitud del fémur tomando en cuenta la edad con el uso de la fórmula: $\mathrm{y}=\mathrm{a}+\mathrm{b}(\mathrm{t})+\operatorname{cln} \mathrm{x}$, donde $\mathrm{t}$ es la edad de la persona $\mathrm{X}$ y clnx es la intersección de la regresión de la longitud del fémur en la edad + edad ln (Lovejoy et al. 1990). La velocidad de crecimiento se calculó como $\mathrm{V}=\mathrm{b}+\mathrm{c} / \mathrm{x}$, que es la primera derivada de la curva a una edad determinada. La significación estadística de las dos curvas se evaluó sobre la base de un Prueba T de la variación de la longitud del fémur en los subadultos.

En cuarto lugar, el estrés en el esqueleto adulto puede estimarse a partir de los patrones de enfermedad, especialmente lesiones no específicas de la periostitis, que se forma bilateralmente con mayor frecuencia en las tibias. La periostitis representa un punto de referencia para medir el estrés adulto, así como su etiología está relacionada con una nutrición adecuada, condiciones de saneamiento deficiente, deterioro de la función inmune, y la exposición a estreptococos y estafilococos (Larsen 2015). 


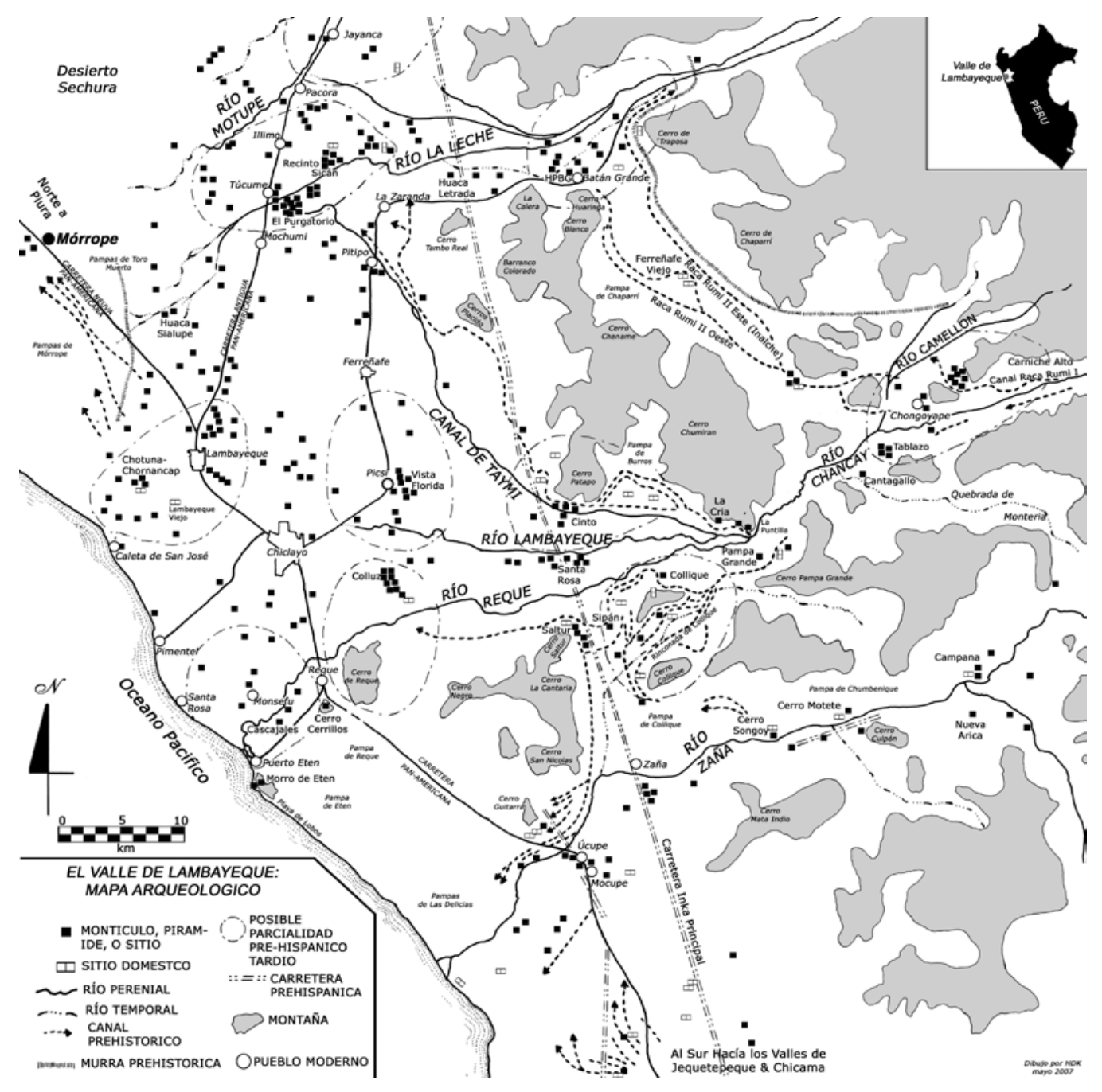

Figura 1. Plano arqueológico del valle de Lambayeque destacando la ubicación de Mórrope (Dibujo: H. Klaus).

En quinto lugar, las estimaciones paleodemográficas de fecundidad poblacional pueden servir como reflejo de la salud de las mujeres. Como la distribución por edades en serie de los esqueletos resulta ser más informativa sobre la profusidad de la mortalidad, la edad media de la muerte está estrechamente relacionada con la inversa de la tasa de natalidad (Sattenspeil y Harpending 1983). Estudios paralelos sobre la energía de las mujeres y la ovulación (Ellison 1994) indican un aumento en el estrés fisiológico y la actividad física que sitúa al cuerpo en un estado energético por debajo del nivel requerido para quedar embarazada o mantener el embarazo (Bogin 2001: 58). En este caso, el ratio D30 + / + D5 + expresa el estimado de la fecundidad, definida como la inversa de la proporción de individuos de más de 30 años (D30 +) sobre el número de personas mayores de cinco años (D5+) (Buikstra et al. 1986). Los resultados se evalúan con una proporción -z. 


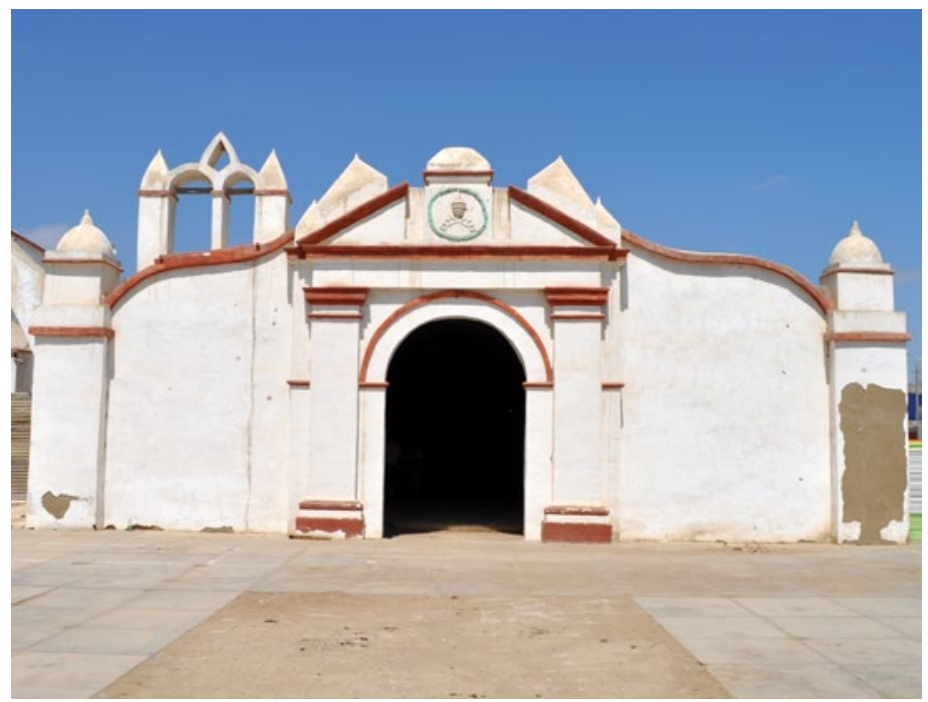

Figura 2. Frontis restaurado de la Capilla de San Pedro de Mórrope (Foto: H. Klaus).

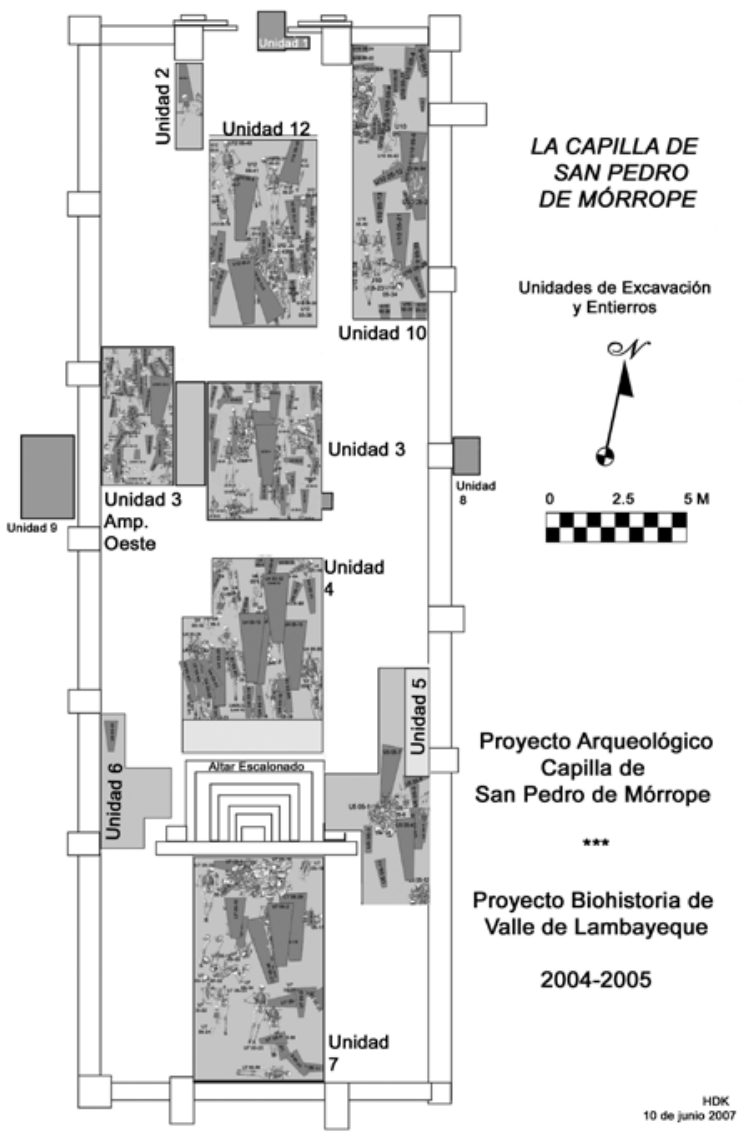

Figura 3. Plano de las excavaciones en la Capilla de San Pedro de Mórrope, mostrando la ubicación de las unidades de excavación y los entierros documentados (Dibujo: H. Klaus). 

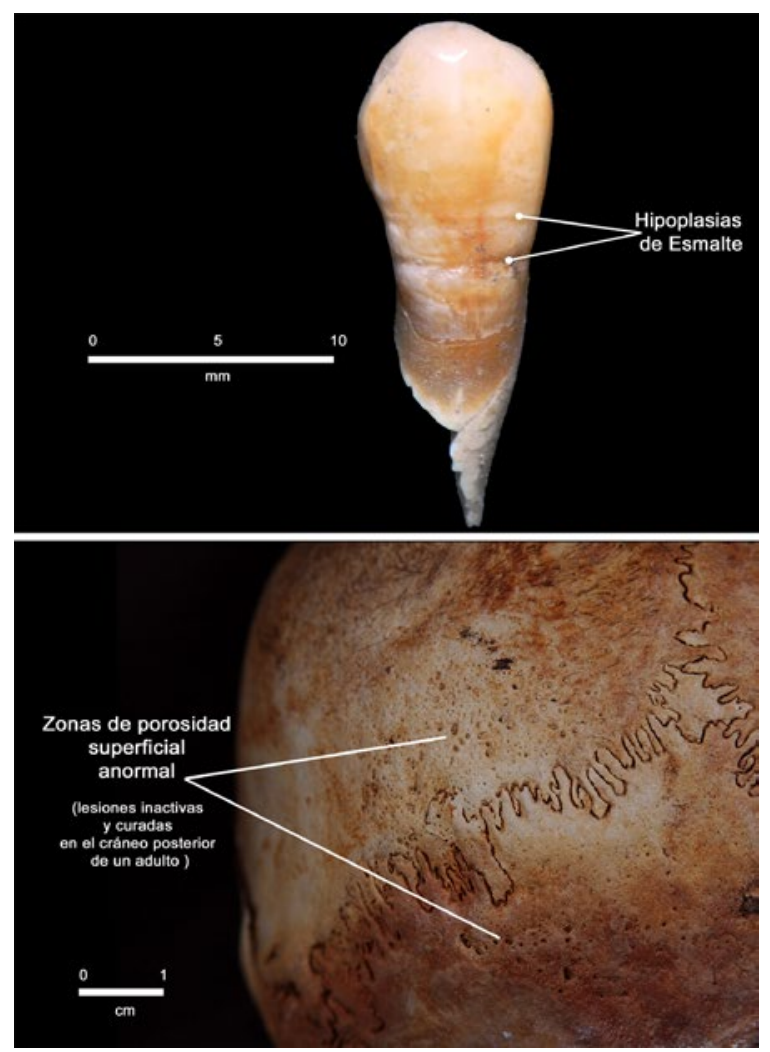

Figura 4. Ejemplos de los condiciones patológicas hipoplasia de esmalte (Entierro U3 03-1 Mandíbula Aislado No 4) e hiperostosis porotica (Entierro U10 05-38) en restos humanos de Mórrope (Foto: H. Klaus).

\subsection{Actividad y estilo de vida}

Desde la década de 1960, los estudios clínicos, epidemiológicos, experimentales y bioarqueológicos han desarrollado una "hipótesis del estrés» que mantiene la osteoartritis como la causa más frecuente de un desequilibrio fisiológico a largo plazo entre el estrés mecánico evidenciado en el tejido de las articulaciones y la capacidad de los tejidos de las articulaciones para soportar el estrés (Merbs 1983; Klaus et al. 2009; Larsen 2015; entre otros). Además, la actividad relacionada con lesiones en las articulaciones - especialmente a temprana edad- puede ser otro factor de riesgo clave en el desarrollo de una enfermedad articular degenerativa (Jurmain 1999). Dado que los cambios artríticos en las superficies articulares abarcan una variedad de enfermedades crónicas, la edad progresiva genera procesos inflamatorios y degenerativos.

La patogénesis de la enfermedad articular degenerativa (EAD, en adelante) es compleja. La degradación del cartílago se divide en tres fases fisiológicas complejas que involucran alteraciones bioquímicas que interfieren con el metabolismo normal de las células promoviendo la pérdida de cartílago. Las respuestas de los huesos van desde el crecimiento excesivo de la formación de hueso compensatoria llamados osteofitos; la muerte del hueso, que se traduce en una superficie conjunta porosa o picada; y los huesos en contacto con el hueso afectado, que conduce a la eburnación - o pulido- y ranurado paralelo a las líneas de movimiento (Figs. 5 y 6). La identificación de actividades físicas específicas en los patrones de $\mathrm{EAD}$ es insostenible, debido a que los movimientos más generales y movimientos habituales parecen accesibles, y son las inferencias apropiadas adquiridas en el estudio de EAD (ver Pearson y Buikstra 2006). 


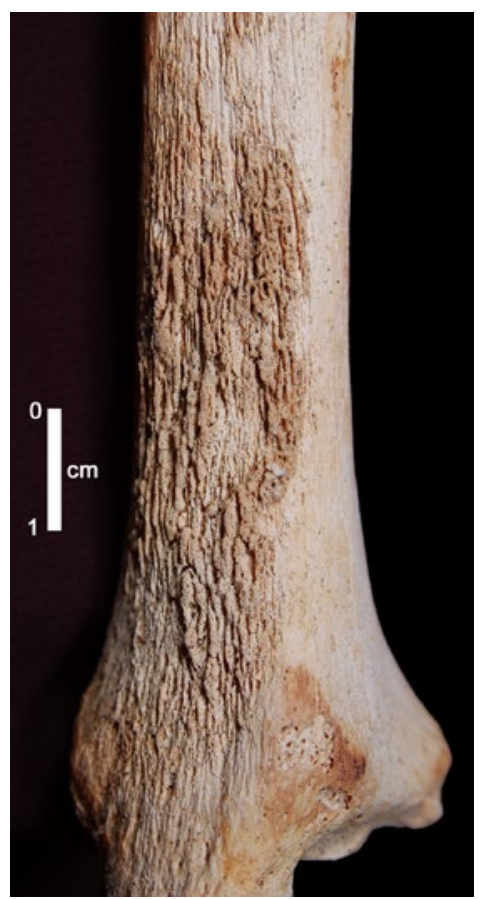

Figura 5. Ejemplo de una formación patológica activa en hueso no normal en la tibia de un individuo de Mórrope (Entierro U4 05-28) (Foto: H. Klaus).
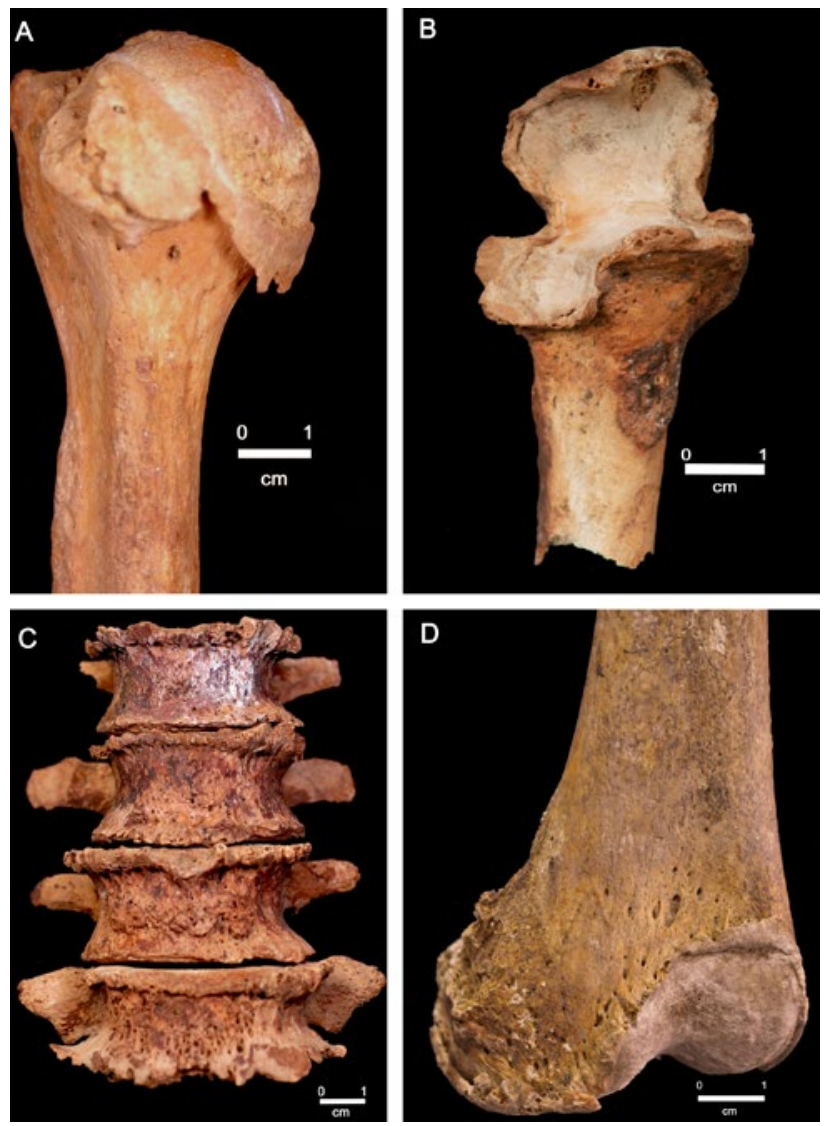

Figura 6. Ejemplos de EAD en Mórrope. Degeneración artritica afectando: $(A)$ hombro (Entierro U7 05-1 Individuo 1); (B) codo (Entierro U3 03-1 Cubito Aislado 12); (C) columna lumbar (Entierro U3 03-4), y (D) rodilla (Entierro U3 05-43) (Fotos: H. Klaus). 


\begin{tabular}{|c|c|c|c|c|c|c|c|c|}
\hline Condición Patológica & $\mathrm{O1}^{\mathrm{a}}$ & $\mathrm{O} 2$ & O3 & O4 & O5 & O6 & ÔR & $x^{21}$ \\
\hline Hipoplasia del esmalte & 5.17 & 7.08 & 5.28 & 0.78 & 2.71 & 0.16 & 1.84 & 4.96 \\
\hline Hiperostosis porótica & 0.62 & 1.02 & 3.02 & 0.88 & 0.41 & 1.45 & 0.98 & 0.003 \\
\hline Periostitis & -.. & $\ldots$ & 0.78 & 0.13 & 0.66 & 0.02 & 0.21 & 14.33 \\
\hline EAD - Hombro & -.- & $\cdots$ & 0.67 & 0.72 & 0.08 & 0.72 & 0.45 & 4.22 \\
\hline EAD - Codo & -.- & $\ldots$ & 0.05 & 0.47 & 1.15 & 0.42 & 0.37 & 11.27 \\
\hline EAD - Muñeca & -.. & $\ldots$ & 0.17 & 0.15 & 0.56 & 0.09 & 0.18 & 13.17 \\
\hline EAD - Mano & -.. & $\ldots$ & 0.61 & 4.09 & 2.33 & 0.15 & 0.74 & 0.38 \\
\hline EAD - Columna cervical & --. & $\cdots$ & 0.92 & 1.63 & 0.58 & 0.20 & 0.57 & 2.04 \\
\hline EAD - Columna torácica & -.. & $\cdots$ & 1.55 & 1.68 & 0.67 & 0.13 & 0.71 & 0.82 \\
\hline EAD - Columna lumbar & -.. & $\ldots$ & 0.83 & 0.85 & 1.17 & 0.27 & 0.70 & 0.91 \\
\hline Nodos de Schmorl & -.. & $\ldots$ & 0.13 & 0.54 & 0.88 & 0.30 & 0.42 & 2.33 \\
\hline EAD - Cadera & -.. & $\cdots$ & 0.54 & 8.50 & 1.33 & 1.09 & 1.78 & 1.63 \\
\hline EAD - Rodilla & -.. & $\cdots$ & 0.05 & 0.29 & 0.57 & 0.44 & 0.28 & 14.35 \\
\hline EAD - Tobillo & -.- & -.- & 1.36 & 6.92 & 0.40 & 1.330 & 1.52 & 0.86 \\
\hline EAD - Pie & -.. & $\ldots$ & 1.25 & 1.24 & 0.70 & 1.54 & 1.20 & 0.11 \\
\hline Lesión Traumática & $\cdots$ & $\ldots$ & 0.58 & 0.78 & 0.97 & 0.97 & 0.64 & 1.33 \\
\hline
\end{tabular}

a. 01 a $O 6$ representan el ratio de probabilidades para las clases de edad individuales $1-6: 1=0-4,9$ años; $2=5$ a 14,9 años; $3=15$ a 24,9 años; $4=25$ a 34,9 años; $5=35$ a 44,9 años; $6=45$ años o más.

b. Las diferencias globales de prevalencia están representados por el ratio de probabilidades, o ÔR. Los valores iguales o superiores a 1.01 representan un mayor prevalencia del pre-hispánico tardio, mientras que los valores iguales o inferiores a 0.99 corresponden a una mayor prevalencia post-contacto. En tales casos, las probabilidades post-contacto reales de mayor prevalencia se calcularon tomando el inverso de valores inferiores a uno de ÔR. El estasis exacto estaria representado por $\mathrm{O} R=1,00$ y $\chi_{1}^{2}=0.00$.

Tabla 1. Cambios en la prevalencia de condiciones patológicas, periodo prehispánico tardio-colonial, valle de Lambayeque, Perú.

Son once los sistemas de articulaciones analizados en este estudio: el hombro, codo, muñeca, mano, vértebras cervicales, vértebras torácicas, vértebras lumbares, la cadera, rodilla, tobillo y pie. Se notó que, para la $\mathrm{EAD}$, el $50 \%$ o más de una superficie articular estuvo presente con un esquema de codificación estandarizado para la localización de la lesión, el tipo y la severidad (Buikstra y Ubelaker 1994). Menos del 20\% de los sistemas de articulaciones afectados exhiben degeneración unilateral que justifica aquí la combinación de los datos de EAD de los lados izquierdo y derecho (Tabla 1).

\subsection{Dieta}

La naturaleza y la estructura de la dieta en el pasado han sido mejor evaluadas, aunque el estudio simultáneo de múltiples variables está relacionado con la salud oral. Aquí evalúo las dos manifestaciones más importantes de la dieta y la biología oral. Primero, la prevalencia de caries dental (un proceso de enfermedad infecciosa) está fuertemente ligada a la proporción de carbohidratos con almidón en la dieta, y su efecto sobre el $\mathrm{pH}$ de la saliva y la ecología bacteriana presente en la placa oral (Hillson 2008). Los azúcares se difunden rápidamente en la matriz de la placa y son fermentados por Streptococcus sp. y Lactobacillus spp., que excretan los ácidos orgánicos que disuelven la matriz mineral. Segundo, la pérdida de dientes antes de la muerte (PDAM) puede deberse a múltiples causas, como la caries dental avanzada, que penetra en la cámara pulpar y fuerza la exfoliación de los dientes muertos, infectados, los que presentan desgaste dental avanzado y trauma (Lukacs 2007) (Fig. 7). Después de la pérdida de dientes, el hueso alveolar se reabsorbe y remodela la toma de vacío. La PDAM fue anotada por el lugar del diente y el grado de reabsorción alveolar.

\subsection{Arqueología mortuoria}

Un total de 27 variables relacionadas con datos básicos funerarios (v.g. procedencia, la construcción de ataúdes, eje, posición de brazos y piernas, etc.) han sido recogidas (Klaus 2008: Apéndice A). 
Un enfoque arqueotanatológico tafonómico fue utilizado también para desarrollar una comprensión más detallada y precisa de la reconstrucción del sistema de deposición de los cadáveres (Klaus y Tam 2014). Entre los 322 entierros, los restos de al menos 867 personas fueron recuperados, e incluyeron, al menos, a 405 subadultos ( $\leq 20$ años) y 371 adultos ( $\geq 21$ ańos).

Los patrones de enterramiento y los datos bioarqueológicos se compararon con muestras de la época prehispánica tardía del valle de Lambayeque $(\mathrm{n}=255)$ procedente de diez sitios en los que están representados todos los estratos sociales y los grupos étnicos conocidos: Sicán, Illimo, Sialupe, Huaca del Pueblo Batán Grande, Cerro Cerrillos y una población provincial enterrado en Huaca Cao Viejo del valle de Chicama (Sicán Medio), Cascajales (Sicán Tardío), La Caleta de San José, Úcupe (Chimú) y Túcume (Inka).

\subsection{Preparación de datos y métodos estadísticos}

Para evitar las posibles deficiencias en la estimación de la edad osteológica tradicional (Jakes 2000), los esqueletos fueron seriados en una secuencia de maduración internamente coherente sin el uso de una población de referencia. Las edades de los subadultos se basaron en el desarrollo de la corona del diente, la erupción de los dientes y las etapas de fusión epifisaria (Scheuer y Black 2000). Las estimaciones de la edad adulta se basaron en la morfología de la sínfisis púbica, superficie auricular y el cierre de las suturas craneanas (ver referencias y normas Buikstra y Ubelaker 1994; Klaus 2008). Utilizando SAS 9.1 (SAS Institute, Inc. 2003) para la recopilación de las edades, estas fueron calculadas y ajustadas a partir de los valores de corrección de sesgo (Lovejoy et al. 1985) para la construcción de seis clases de edad ( 0 a 4,9; 5-14,9; 15-24,9; 25-34,9; 35-44,9; y 45 años y más).

La medición de la prevalencia de la enfermedad no es sencilla. A menudo, bioarqueólogos o paleopatólogos utilizan estimaciones brutas de prevalencia (número de individuos afectados dividido por el tamaño de la muestra total) que pueden alterar o tergiversar la prevalencia verdadera. La prevalencia de la enfermedad en una muestra de esqueletos es una función de la distribución de edades. Las muestras con mayor proporción de personas de edad avanzada tienen una mayor probabilidad de haber acumulado más patología, debido a que han vivido más tiempo y viceversa. En consecuencia, HEL, la hiperostosis porótica y la periostitis, fueron recodificadas como presente o ausente, y la prevalencia específica de la clase de edad se calculó utilizando un ratio de probabilidades (Waldron 1994) en el software SAS 9.1. Cuando se suman y se dividen por el tamaño de la muestra total, un ratio de probabilidades común (ÔR) genera una relación entre la edad y la prevalencia específica proporcional en dos poblaciones con un solo número. Los odds-ratio son probablemente el mejor método para comparar la prevalencia entre las dos poblaciones. Prevalencia de caries dentales y PDAM fueron calculados por separado para numerosas lesiones en dientes anteriores (incisivos y caninos) y posteriores (premolares y molares) en cada clase de edad, porque están en situación de riesgo diferenciado para estas condiciones debido a su morfología. La significación estadística se determinó mediante una Prueba-G, o una chi cuadrado $(\chi 2)$ de máxima verosimilitud. Esto es ideal para pequeñas submuestras $(<50$ personas) de datos continuos como estos. Cuando la diferencia entre la frecuencia absoluta observada $(\mathrm{O})$ y la frecuencia esperada $(\mathrm{E})$ es mayor que los valores esperados, una prueba de $\chi 2$ puede llegar a ser artificialmente inflada. El Prueba-G evita esto utilizando la frecuencia del valor esperado en el denominador. Tomando el logaritmo natural de esta relación, cada registro se multiplica por $\mathrm{O}$, y los productos son sumados y multiplicados por 2, tal que $G=2 \sum(\mathrm{O} \ln [\mathrm{O} / \mathrm{E}])$ (Sokal y Rohlf 1995).

\section{Resultados}

\subsection{Los restos humanos}

La prevalencia total de HEL disminuye de manera significativa y es 1,8 veces menos común entre los muchik poscontacto de Mórrope. La prevalencia de la hiperostosis porótica aumenta significativamente 1,54 veces en Mórrope poscontacto en comparación con la época prehispánica tardía. 


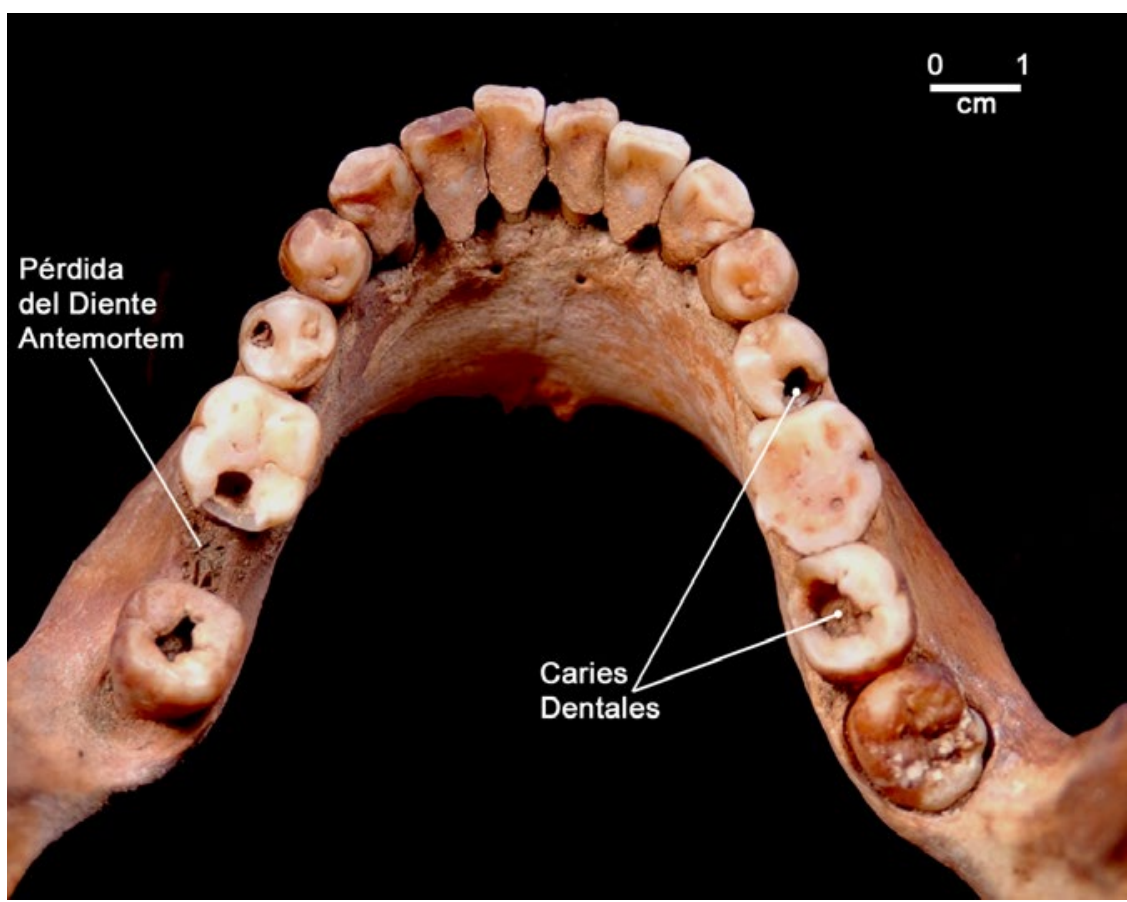

Figura 7. Ejemplos de caries dentales y pérdida de dientes antemortem en Mórrope (Entierro U5 05-4) (Foto: H. Klaus).

El análisis del crecimiento del fémur revela un crecimiento subadulto deprimido en Mórrope y es significativamente menor que la muestra prehispánica $(T=4,70 ; \mathrm{p}=<0,0001)$ a las edades de 5,10 y 12 ańos. Los datos sugieren que los subadultos de Mórrope estaban creciendo entre tres y cuatro milímetros por año más lento que los niños del período prehispánico tardío. Entre los adultos, la infección de periostitis es 4,71 veces más probable entre las personas poscontacto en Mórrope. Las diferencias en la D30 + ( $\mathrm{z}=-1,61 ; \mathrm{p}=0,05)$ y D $5+(\mathrm{z}=1,76 ; \mathrm{p}=0,04)$ entre las proporciones de las muestras prehispánicas tardías y poscontacto son significativas. La estimación de la fertilidad con la relación D30 + / + D5+ indica una disminución general de 0,4397 (prehispánica tardía) frente a 0,6028 (Mórrope colonial).

Se observa una elevación significativa de la EAD en los sistemas de articulación de la extremidad superior: la articulación del hombro poscontacto es 2,2 veces más propensa a ser afectada por EAD que la población del período prehispánico tardío. La prevalencia también aumenta 2,7 veces en el codo y DJD es 5,6 veces mayor en la muñeca para el caso de Mórrope. El único cambio significativo en el miembro inferior se encuentra en la articulación de la rodilla, en la que resultó elevada la prevalencia de EAD poscontacto en 3,6 veces. Los odds-ratio por categoría de edad revelan que la mayor magnitud de cambios significativos poscontacto se concentra a menudo en las clases de edad más jóvenes, 3 y 4 . EAD en el codo y la rodilla, por ejemplo, es 20 veces más probable entre la clase de edad 3, adultos poscontacto jóvenes (Tabla 1).

Las comparaciones de las lesiones anteriores por caries dental muestran que la prevalencia en bruto es muy elevada en denticiones en Mórrope colonial, pero solo alcanza significación estadística en las clases de edad 2 y 3 . Del mismo modo, las frecuencias discontinuas y elevadas de caries dental se observan en los dientes posteriores de la población de Mórrope poscontacto y son estadísticamente significativas en las clases de edad 4 y 5 . La prevalencia poscontacto muy elevada de la pérdida de los dientes anteriores y posteriores antes de la muerte es significativa en tres grupos de edad: 4,5 y 6 (Tabla 2). 


\begin{tabular}{|c|c|c|c|c|c|c|c|c|c|c|}
\hline \multirow[t]{2}{*}{ Clases de Edades a } & \multicolumn{2}{|c|}{ Caries Ant. ${ }^{b}$} & \multicolumn{2}{|c|}{ Caries Post. ${ }^{c}$} & \multicolumn{2}{|c|}{ PDAM Ant. ${ }^{d}$} & \multicolumn{2}{|c|}{ PDAM Post. } & \multicolumn{2}{|c|}{ Abscesos } \\
\hline & $\mathbf{G}^{\mathrm{e}}$ & $p^{\prime}$ & G & $p$ & G & $p$ & G & $P$ & G & $p$ \\
\hline 2 & 0.62 & 0.43 & 0.33 & 0.56 & 0.73 & 0.39 & $\cdots$ & $\cdots$ & $\cdots$ & $\cdots$ \\
\hline 4 & 1.50 & 0.22 & 36.19 & 0.0001 & 7.35 & 0.007 & 8.93 & 0.003 & $\cdots$ & $\cdots$ \\
\hline 5 & 0.12 & 0.72 & 0.03 & 0.86 & 37.70 & 0.0001 & 10.66 & 0.001 & 0.89 & 0.35 \\
\hline 6 & 3.65 & 0.05 & 0.49 & 0.48 & 4.35 & 0.04 & 1.62 & 0.20 & 5.21 & 0.23 \\
\hline
\end{tabular}

a. Clases de edades definidas en la Tabla1.

b. Los dientes anteriores definidos son los incisivos y caninos (Ant.).

c. Los dientes posteriores definidos son premolares y molares (Post.).

d. PDAM = Perdida dental antemortem.

e. Valor G-estadistico (también llamado cociente de probabilidad chi-cuadrado); un grado de libertad.

f. Valor $p$ o probabilidad de $\mathrm{G}$.

Tabla 2. Cambios en la prevalencia de la salud oral, periodo prehispánico tardio-colonial, valle de Lambayeque, Perú.

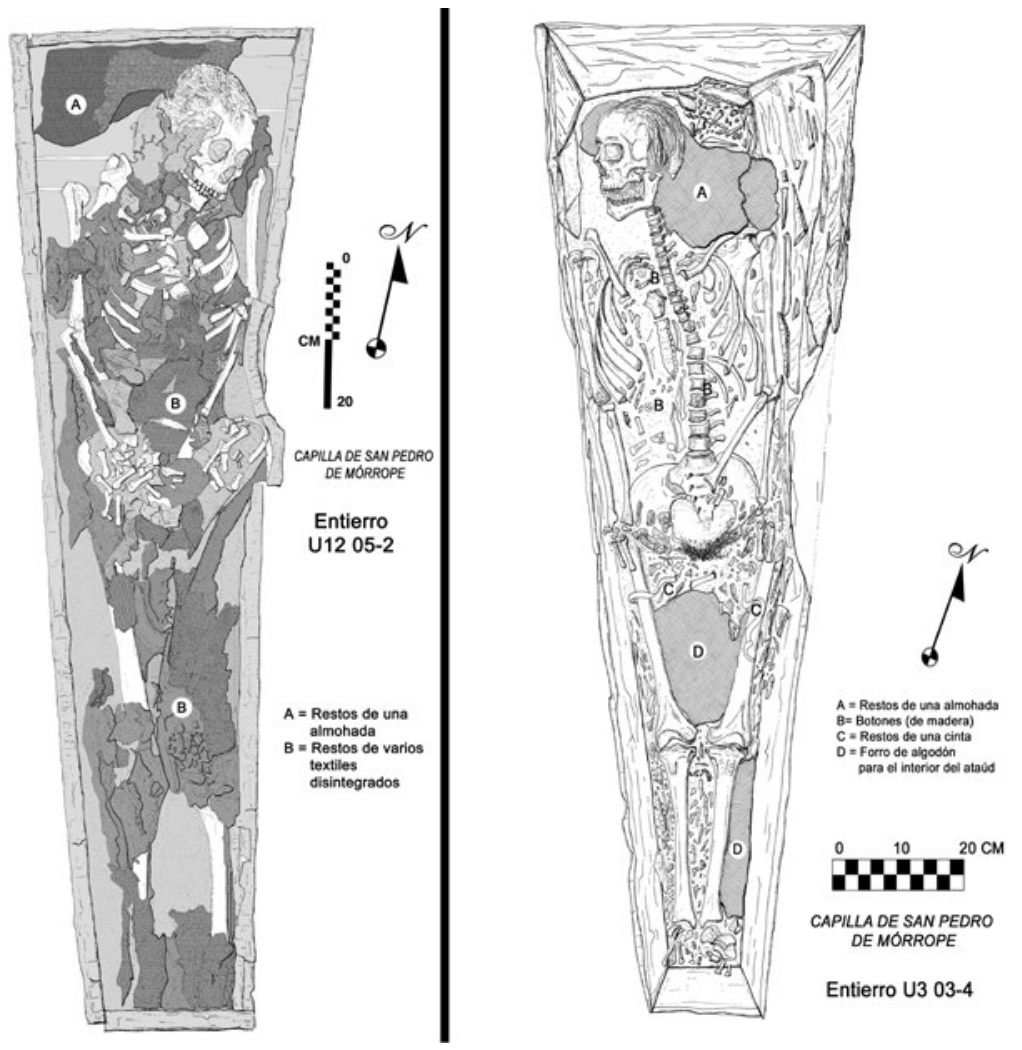

Figura 8. Ejemplos del patrón funerario básico en Mórrope colonial: Entierro U12 05-2 (izquierdo) y Entierro U3 03-4 (derecho) (Dibujos: H. Klaus). 


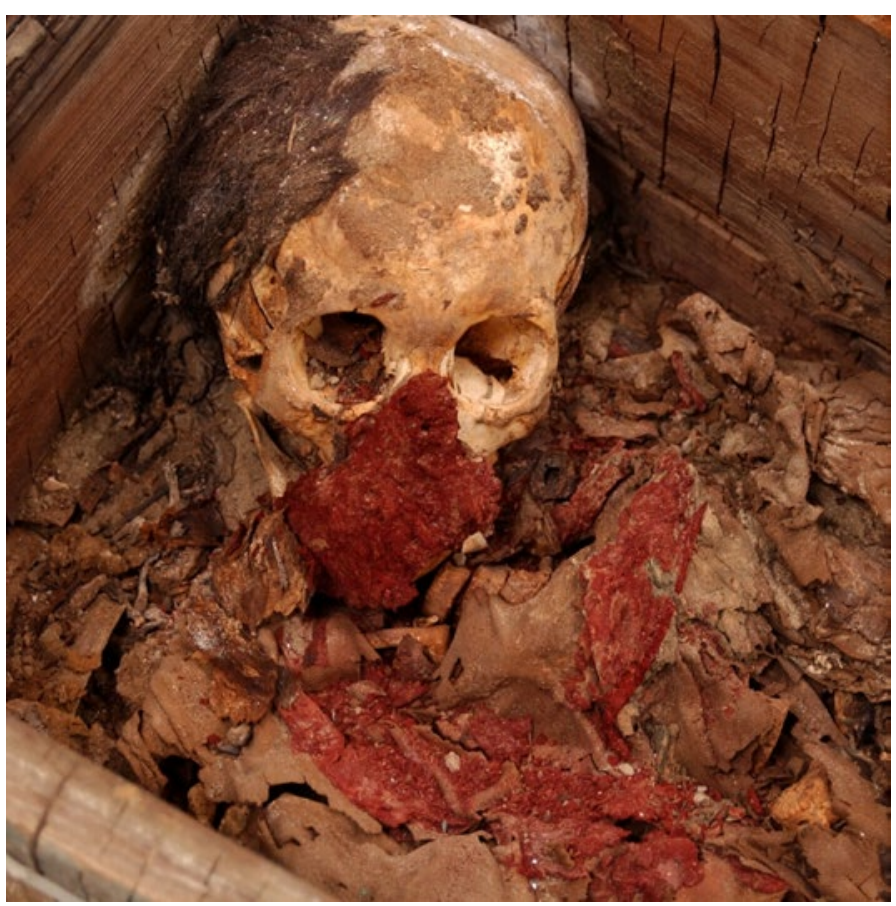

Figura 9. Uso de un textil rojo para cubrir la cara de un niño (Entierro U3 05-12) en Mórrope colonial (Foto: H. Klaus).

\subsection{Las prácticas funerarias}

Superficialmente, los entierros de Mórrope parecen la quintaesencia cristiana. Los cuerpos eran colocados en ataúdes hechos de tablones de madera adornada con decoraciones de cobre que formaban cruces cristianas. Los fragmentos de textiles y calzados de cuero indican que muchos de los muertos estaban vestidos con ropas europeas. El uso precontacto de ofrendas funerarias, incluidas vasijas de cerámica, metales y ofrendas de camélidos, estaban completamente ausentes. Sin embargo, una mirada más cercana revela prácticas que tienen antecedentes prehispánicos directos en el valle de Lambayeque y la Costa Norte del Perú en general. Las iglesias católicas y los entierros de la época fueron supuestamente alineados en un eje este-oeste, con la cabeza del difunto que miraba hacia el este para que los muertos puedan resucitar de frente al regreso de Cristo. En Mórrope, prácticamente, todos los enterramientos e incluso la propia iglesia se alinean con el eje muchik: la tradicional orientación norte-sur de los muertos y de los principales centros ceremoniales-cívicos al menos desde 1500 a.C. (Figs. 3 y 8).

El hallazgo de pigmento rojo alrededor de la cara de más de 60 entierros en Mórrope se asoció con el uso prehispánico de cinabrio. El cinabrio, una hematita de mercurio, también se utilizó a nivel regional para ungir la cara de los muertos de alrededor de 1500 a.C. Aquí, los textiles teñidos de rojo cubren el rostro de la persona fallecida y el pigmento orgánico carecía de la brillantez de cinabrio. Sin embargo, parece que esto representa el intento de la época colonial de reproducir esta tradición. Adyacente a por lo menos dos tumbas coloniales tempranas, se han documentado restos de quema in situ, lo cual correspondería a una práctica local reconocida en ca. 900-1100 d.C., que implicaba realizar incendios rituales cerca o dentro de una tumba antes de ser enterrada (Shimada et al. 2014) (Fig. 9).

En las prácticas funerarias católicas, los muertos deben descansar tranquilos hasta la Segunda Venida. Sin embargo, las observaciones tafonómicas indican que casi la mitad de los entierros fueron alterados por las actividades humanas intencionales. Restos de pupas de mosca vacías en más 


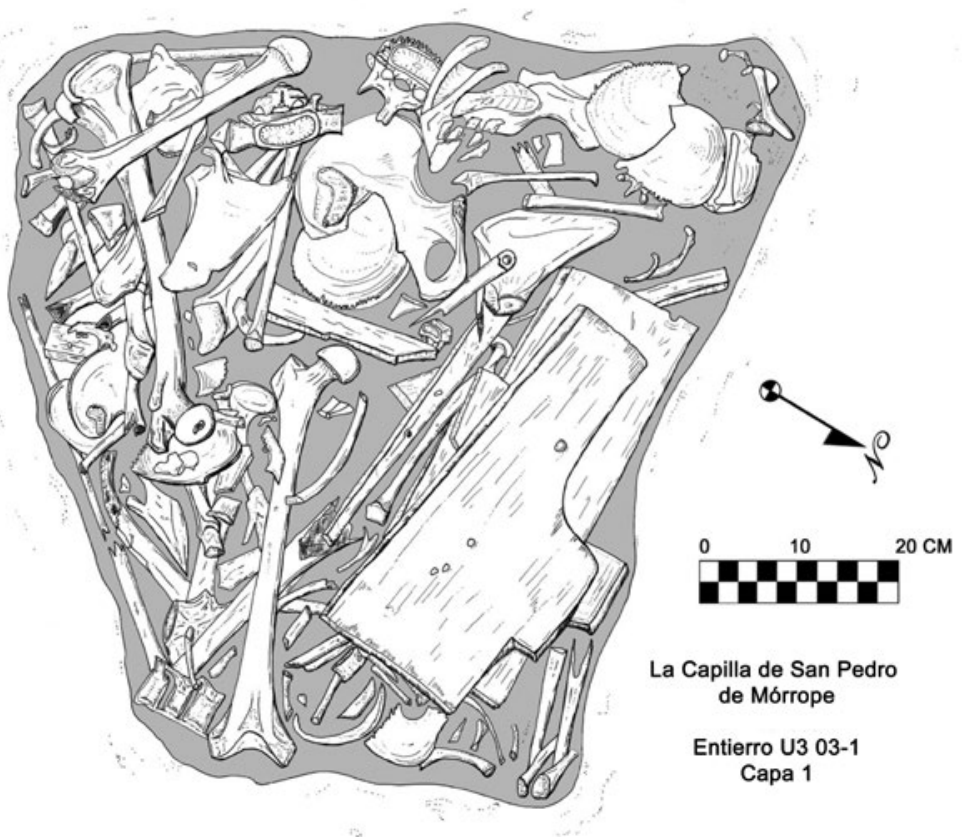

Figura 10. Un entierro secundario en Mórrope (Entierro U3 03-1). Si bien puede parecer desorganizado en su diseño, el contenido interno refleja un patrón claro visto en todo el sitio que implica la clasificación y selección de los huesos largos y el cráneo (Dibujo: H. Klaus).

de una docena de ataúdes de los niños indican tal vez un mes o más tiempo transcurrido entre la muerte y el entierro, según lo sugerido por los datos entomológicos forenses (Haskell et al. 1997). Esta práctica evidencia paralelos entre las formas de enterramiento prehispánico de la Costa Norte, el arte moche y las fuentes etnohistóricas que sugieren un ritual indígena de participación de transferencia del alma (Bourget 2001). Cincuenta y un entierros secundarios fueron documentados; estos no fueron las colecciones de los cuerpos exhumados y vueltos a depositar para dar paso a nuevos entierros, sino que representan entierros rituales, en su mayoría, cráneos y huesos largos (Klaus y Tam 2014). En otros casos, las fosas y los ataúdes fueron abiertos; y los cráneos y huesos largos, manipulados, eliminados o añadidos de forma idéntica a las prácticas prehispánicas recientemente documentadas, quizás, relacionadas con rituales sobre la fertilidad de los muertos en la Costa Norte y central (Klaus 2013) (Figs. 10, 11 y 12).

\section{Discusión}

El impacto de la colonización española en el pueblo de Mórrope fue complejo y multifacético. Las múltiples líneas de datos examinados en este estudio revelan que muchos tipos diferentes de experiencias vividas y los fenómenos culturales se desarrollaron en este rincón del valle de Lambayeque en Perú. En esta sección, trato de ofrecer algunas interpretaciones con respecto a la significancia social, económica y ecológica de estos patrones para utilizar un enfoque contextual e integrar la evidencia etnohistórica y arqueológica.

\subsection{Efectos de la agregación poblacional}

Los efectos biológicos de la Conquista fueron transmitidos con claridad por todos en Mórrope, pero los niños son quizás los más sensibles al estrés biológico. Mientras la hiperostosis porótica fue 

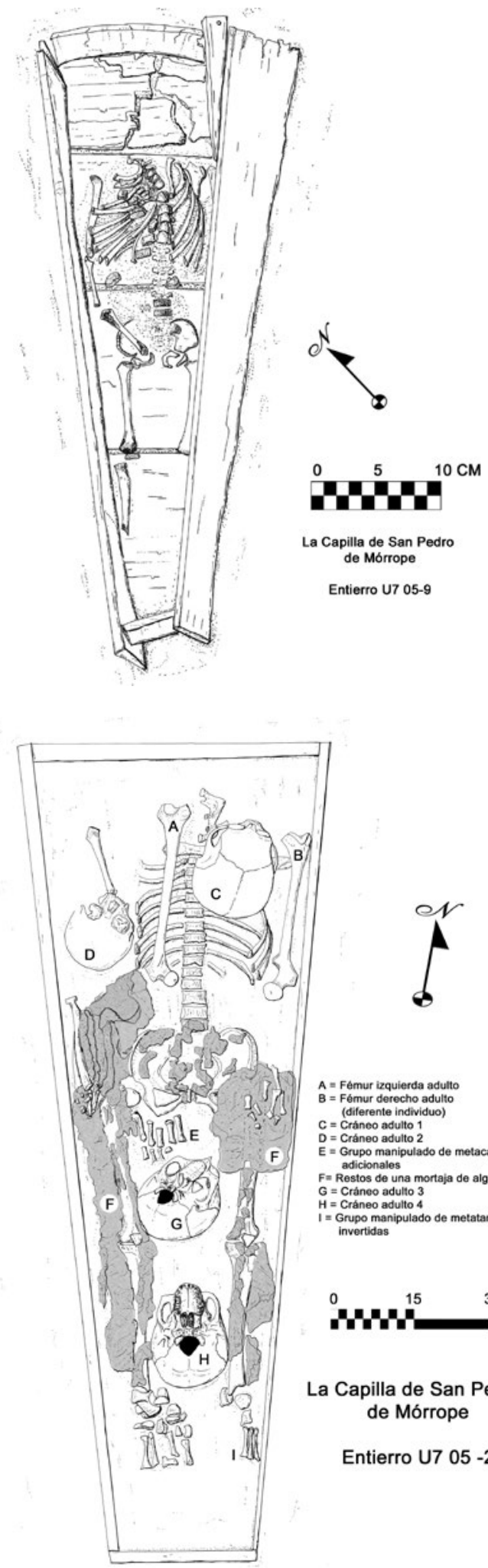

Figura 11. Un buen ejemplo de la selectividad en la alteración y remoción de los elementos de esqueletos en Mórrope (Entierro U7 05-9) (Dibujo: H. Klaus).

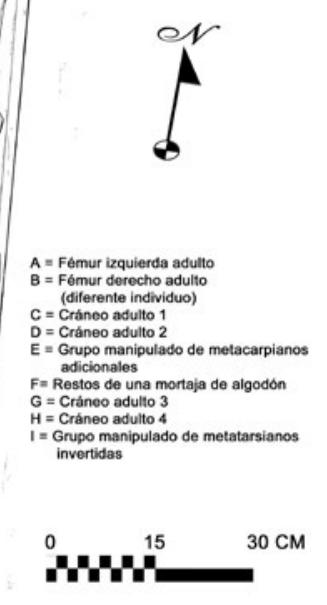

La Capilla de San Pedro de Mórrope

Entierro U7 05 -2
Figura 12. Mórrope Entierro U7 05-2 sirve como en ejemplar de los formas y prácticas de manipulación, remoción, y simbolismo prehispánico en la interacción entre los morropanos coloniales y sus muertos (Dibujo: H. Klaus). 
concebida una vez como un reflejo directo de insuficiencia de hierro biodisponible en la niñez, una variedad de factores ecológicos y sociales son ahora conocidos como clave de su etiología múltiple - probablemente relacionada en mayor medida con la insuficiencia nutricional de vitaminas B9 y B12 (anemia megaloblástica)—, impulsados por una nutrición insuficiente, infecciones gastrointestinales crónicas (Kent 1986; Walker et al. 2009) y una menor biodisponibilidad de B12. Mientras que los adultos mantienen las reservas de vitamina B12 en el hígado, los niños no lo hacen y son mucho más susceptibles a la anemia megaloblástica inducida por B12. La principal fuente de vitamina B12 es la carne de los animales y muchos niños en Mórrope consumieron una menor proporción de carne que sus antepasados prehispánicos (véase también la discusión sobre la dieta, más adelante). Otras condiciones potenciales para el incremento de anemia también se indican. Se afirma que los morropanos cultivaron frijoles y maíz en su mayoría con deficiencia de B12. Algunas evidencias arqueológicas y nuestro análisis inicial isotópico del colágeno de las costillas de varios restos humanos de Mórrope revelan que los alimentos marinos explotados, como Donax sp., fueron los factores que conllevaron un riesgo de anemia inducida por el parasitismo, la pérdida de sangre y la infección (Walker 1986).

Del mismo modo, la depresión de crecimiento del esqueleto es un fenómeno multifactorial, pero la infección gastrointestinal es una causa bien establecida de retraso en el crecimiento lineal de los huesos largos (Martorell et al. 1975). Sinérgicamente, la deficiencia de vitamina B12 contribuye a este proceso. El primer cambio negativo en la velocidad de crecimiento entre las edades de dos a cinco años en Mórrope puede haber sido iniciado por el cese de la lactancia materna (que proporciona la inmunocompetencia pasiva y una fuente libre de agentes patógenos de los alimentos) y la introducción de una dieta de alimentos sólidos contaminados.

Entre los adultos de Mórrope, la infección no específica de periostitis aumentó 471\%. Esto es totalmente consistente con las condiciones etnohistóricas conocidas de densidad poblacional elevada y un saneamiento deficiente. La disminución de la fertilidad femenina también es consistente con estas condiciones. Por otra parte, el análisis de odds-ratio de periostitis en las mujeres de Mórrope, muestra un salto significativo de las tasas entre las mujeres prehispánicas (Klaus y Tam 2009a), por lo que las infecciones repetidas pueden representar una fuga de energía en la fertilidad. Además, diversas fuentes históricas caracterizan a las mujeres indígenas andinas como ampliamente manipuladas como "mano de obra cautiva», condición íntimamente relacionada con tal reducción (Graubart 2000). Las mujeres muchik contribuyeron en gran medida con la mayoría de los sectores de la economía, lo cual es consistente con los análisis de odds-ratio, que demuestran la elevada prevalencia de la EAD en casi todos los sistemas conjuntos femeninos (ver Klaus et al. 2009). La vida dentro de la reducción, el trabajo poscontacto, una tasa de infección femenina elevada y una menor calidad en la dieta a menudo disminuyen el metabolismo de las mujeres por debajo de los mínimos de energía al quedar embarazadas.

Los patrones de HEL en Mórrope fueron muy diferentes a nuestro contexto y todas las otras expresiones de estrés biológico aumentado. Tres posibles explicaciones pueden ser consideradas. En primer lugar, un sesgo de muestreo no detectado en la actualidad puede tener una representación errada. En segundo lugar, Mórrope pudo haber experimentado una rápida selección natural y el éxito de su adaptación, pero esto sería incompatible con todas las indicaciones de deterioro de la salud. En tercer lugar, es posible que la tensión aguda en la infancia pasara de una supervivencia metabólica a una infección con alta mortalidad. Las poblaciones andinas han sufrido varias olas de enfermedades epidémicas en el siglo XVIII (Cook 1981). Las formas más significativas de estrés biológico en Mórrope probablemente tomaron la forma de viruela, sarampión, gripe, paperas, rubéola y escarlatina. Muchos de los niños probablemente no sobrevivieron a estas infecciones para formar hipoplasia del esmalte, en primer lugar. El patrón bajo de HEL poscontacto demuestra la fuerte magnitud de disminución en las clases de edad 1, 2 y 3 (los no sobrevivientes de estrés infantil), que es seguida por una mayor prevalencia en las clases de edad de 4 y 6 (los sobrevivientes inferidos). Nuestra hipótesis de trabajo sostiene que, dada la invisibilidad en el esqueleto de las enfermedades epidémicas, la disminución de la prevalencia en HEL poscontacto en Mórrope 
puede subestimar la morbilidad e indirectamente reflejar los efectos de la elevación aguda de estrés biológico en subadultos (Cohen y Crane-Kramer 2007: 346).

En total, estas cinco variables independientes representan expresiones fisiológicas de estrés biológico con experiencia en diferentes etapas de la historia de vida. Sin embargo, estas experiencias de estrés pueden ser unificadas por la naturaleza de un pueblo del Perú colonial. Con la excepción del asentamiento urbano moche de Pampa Grande (Shimada 1994), los asentamientos prehispánicos del valle de Lambayeque fueron relativamente dispersos y tuvieron una baja densidad poblacional. Como los estudios arqueológicos en torno a Mórrope indican, la mayoría de las comunidades locales de la época prehispánica tardía se caracterizan por la presencia de varios montículos de casas dispersos y que soportaron a no más de 50 a 100 personas en cada pueblo. Sin embargo, un elemento central de la política española fue la creación de poblados indígenas a los que se les podía aplicar impuestos, así como controlar su fuerza de trabajo. En Mórrope, la vida en reducción no tenía precedentes. Para 1548, la población de Mórrope, estimada en 2000 o más, habría representado un incremento del $400 \%$ en su densidad poblacional. La reunión repentina y sostenida, propia de las reducciones, generó un nuevo medioambiente a nivel micro y un nuevo conjunto de factores de estrés biológico. En esencia, la adopción de esta nueva política socioeconómica creó un «reactor de enfermedades» y un patrón de asentamiento, que tuvo consecuencias biológicas intrínsecamente negativas: el riesgo elevado de exposición a los individuos enfermos, desechos producto de actividad humana, una estrecha interacción con cabras y mulas domésticas, la falta de saneamiento, agua contaminada, y las zoonosis solo se ven agravados por la condición marginal ecológica de la región noroeste de Lambayeque. El aumento de la prevalencia de hiperostosis porótica y el crecimiento deprimido en Mórrope colonial puede estar especialmente vinculado con la reunión de la población. El aumento de la población aumentó la exposición a una amplia variedad de vectores como moscas, roedores, perros, bacterias (por ejemplo, Escherichia coli, Shigella, Salmonella), virus (por ejemplo, parvovirus y rotavirus) y parásitos (por ejemplo, los helmintos, protozoarios o infecciones amebianas) (Kent 1986).

Estos factores son consistentes con los patrones de estrés poscontacto observados. Si, como hipótesis, la baja prevalencia de HEL es un signo indirecto de la infección con alta mortalidad, un asentamiento denso habría sido una condición ideal para la transmisión de enfermedades epidémicas. La densidad de población y la falta de saneamiento en Mórrope podría haber impulsado la anemia infantil y el crecimiento prepuberal deprimido solo con la ocurrencia de infecciones gastrointestinales crónicas. Una elevada infección crónica de periostitis es, quizás, una de las variables más directamente relacionada con una mayor densidad poblacional. En el caso de las mujeres, estas experimentaron una mayor carga infecciosa crónica, lo que, sumado al arduo trabajo como parte de la economía doméstica y la producción ligada a la vida en la reducción, condujo a que su fecundidad disminuyera.

\subsection{Actividad física y estilo de vida}

En comparación con la época prehispánica, el Perú colonial podría ser caracterizado como un período de extraordinaria intensificación económica relacionada con los objetivos comerciales europeos (Contreras 2009, 2010). A medida que la economía colonial se desarrollaba, la mano de obra indígena fue utilizada como la principal fuerza productiva. Alejado de los vastos campos de caña de azúcar en otras partes del valle, Mórrope representó un lugar único que abarcó tres sectores de este nuevo orden: la minería, la agricultura y el pastoreo. La zona inmediatamente al norte y al oeste de Mórrope fue alguna vez una amplia ensenada sumergida en el mar, que emergió y se llenó de sedimentos en los últimos 60 millones de años, para formar extensos depósitos de yeso, sal y fosfatos (Collin Delavaud 1984). La Iglesia, en particular, fue capaz de sacar provecho de los recursos mineros mediante la manipulación de los muchik de Mórrope. Los sacerdotes exigían el pago de tributos y rentas eclesiásticas a través de cuotas de minería (Peralta 1998; Figueroa e Idrogo 2003). Las protestas muchik contra los alquileres excesivos se registraron en 1689 y 1712 , y, 
en este último caso, el sacerdote respondió al aumentar las cuotas de los tributos mineros (Rubiños y Andrade 1782 [1936]).

La vinculación de los patrones particulares de EAD a actividades físicas especificas es injustificada e inviable, pero es posible considerar articular las posibles asociaciones de patologías en Mórrope con estas líneas de contexto etnohistórico documentado. El uso extenuante y habitual de los miembros superiores, la flexión repetitiva del torso y las rodillas, y el levantamiento manual de cargas pesadas asociados a estas actividades son biológicamente compatibles con los patrones de uso que se han podido inferir en conjunto en la población poscontacto observada.

La zona de monte se adapta también al pastoreo, que fomenta tales actividades. Como se señaló anteriormente, Mórrope se asienta en la entrada natural del Camino Real que va de Quito a Lima y unía Lambayeque con el valle de Piura. El movimiento de información, bienes y caravanas de mulas y cabras en el norte, le valieron a la población de Mórrope el apelativo de "caminantes del desierto", ya que atravesaron aproximadamente 160 kilómetros entre Mórrope y Piura hasta principios de siglo XIX (Peralta 1998). Tales descripciones podrían anticipar la observación de EAD elevados en los sistemas de articulación de las extremidades inferiores. Sin embargo, una gran cantidad de datos indica que las extremidades inferiores se adaptan bien a la locomoción bípeda. El caminar es un pobre provocador de EAD en las extremidades inferiores (Jurmain 1999).

El aumento de EAD en Mórrope se puede interpretar en términos biológicos de la desigualdad cultural y económica forjada por el contacto con los espańoles. En la Costa Norte del Perú, los pueblos indígenas se vieron forzados a vivir en el más bajo de los niveles de una sociedad jerárquica rígida. Esta desigualdad les impidió escapar de la pobreza. Con su mano de obra explotada, el resultado fue un aumento de la prevalencia de lesiones entre los nativos DJD, que pone de relieve cómo los organismos indígenas fueron empleados en ese entonces para la extracción de recursos. La forma específica en que la intensificación económica poscontacto se llevó a cabo en Mórrope puede estar en gran parte asociada con la fisiogeografia. La manera biológicamente destructiva en que el pueblo de Mórrope experimentó el nuevo sistema económico puede haberse manifestado directamente en forma de variaciones micro-medioambientales, es decir, los suelos salinos, la escasa disponibilidad de agua y amplia de yeso, sales, así como los depósitos de fosfato. Este no pretende ser un punto de vista determinista que sostiene que el muchik de Mórrope fue condenado a la mala suerte. En cambio, la proximidad a algunos de los recursos (minerales) y la lejanía de otros (suelos aluviales) se redujo o centró en la gama de posibilidades económicas específicas.

\subsection{Cambios dietéticos}

El aumento de la prevalencia de las caries dentales y la pérdida de dientes antes de la muerte en Mórrope parecen significar un cambio poscontacto de la dieta. La elevación de caries dentales se manifiesta por primera vez en la dentición anterior de los adolescentes y adultos jóvenes (clases de edad 2 y 3), y se convierte en significativamente mayor en la dentición posterior de las personas mayores (clases de edad de 4 y 5). Mientras que Lambayeque fue el corazón de la industria azucarera del Perú colonial, el azúcar fue exportado y no entró en la dieta local en cantidades significativas (Keith 1976). En cambio, el aumento de las cantidades de azúcares de la dieta, comenzando en la niñez, provino con mayor probabilidad de derivados de cultígenos con almidones. El aumento de PDAM en los dientes anteriores y posteriores también se observa entre los adultos poscontacto. Las muestras pre y poscontacto comparten grados estadísticamente equivalentes de desgaste dental, periodontitis, inflamación apical, lesiones faciales traumáticas y la dureza de la dieta (Klaus y Tam 2010); el riesgo de evulsión del diente de estas fuentes es igual. Por lo tanto, el patrón de PDAM poscontacto es más probable como una función del número mayor de caries dental.

En el Perú colonial, los europeos reconocieron rápidamente las condiciones favorables de la Costa Norte para la producción a escala industrial de los cultivos comerciales: temperaturas moderadas, un clima relativamente soleado, el potencial de los puertos marítimos, grandes extensiones de tierra cultivable y una población indígena acostumbrada a un sistema de trabajo bajo tributo 
(Shimada 1994). Con la reconversión de las regiones ribereñas en fincas de caña de azúcar, las comunidades nativas fueron reasentadas por la fuerza a zonas ecológicas marginales, descritas como "enfermizas», pero el tributo y la producción de subsistencia ya habían sido previstos (Ramírez 1996: 33). Los cultivos de caña de azúcar, alfalfa y otros fueron consumidos en enormes cantidades, y dejaron poco para la agricultura indígena (Ramírez 1996). El ganado vagaba libremente en las fincas sin indígenas para llevarlos a pastar. Los porcinos se hicieron famosos por el desarraigo y por comer los cultivos de subsistencia de la década de 1540. Los animales de pastoreo destruyeron canales y acequias. Muchos canales estuvieron llenos de sedimentos y escombros hasta el momento de su abandono (Netherly 1984).

La masacre generalizada de rebaños de camélidos costeros ocurrió durante las primeras guerras civiles españolas. Las plagas entre las llamas (caracha) en 1544-1545 contribuyeron a la pérdida de fuentes de proteínas tradicionales (Shimada y Shimada 1985: 21). La preferencia europea por incluir a los cerdos en la dieta (pobres en proteínas y con un alto contenido de grasas), y el énfasis en la exportación de jabón y cuero producido terminaron con la extinción regional de camélidos hacia el año 1600. Durante la visita de Gregorio González de Cuenca en Lambayeque, entre 1566 1567, se emitieron ordenanzas que prohibieron el consumo de cuy, perros y los productos derivados del algarrobo (Figueroa e Idrogo 2004: 119). Los alimentos, especialmente la carne, se convirtieron en mercancía en el contexto de una economía basada en el consumo en la Costa Norte colonial. Forzados a una "trampa de pobreza» por la ausencia de autonomía política (Stern 1982), los andinos indígenas, incluidos los muchik, habrían encontrado acceso a alimentos nutritivos que a menudo estaban fuera de su alcance.

Una síntesis de los datos anteriores indica que los datos referentes a la salud bucal son más consistentes con el pueblo de Mórrope frente a la intensificación de la explotación de los cultígenos con almidón en respuesta a las deficiencias en la dieta, la falta de acceso regular a fuentes tradicionales de alimentos y el reasentamiento en áreas de escasos recursos. Es decir, el aumento del consumo de carbohidratos, probablemente, representó una estrategia independiente de los Muchik como «alimentos de reserva». A la par, Mórrope tuvo un medioambiente a nivel micro de tipo marginal, con escaso acceso al agua de riego, de modo que la dinámica de interacción hombremedioambiente en el norte de Perú produjo alimentos aún en circunstancias difíciles (Shimada 1994). Las estrategias creativas de subsistencia en Mórrope probablemente se aplicaron en las pequeńas parcelas agrícolas o chacras, vinculadas por los hogares fuera del ámbito de la economía política colonial.

Durante la época colonial en Mórrope, la mayor explotación de carbohidratos (largos polímeros de azúcar) habría proporcionado una dieta menos nutritiva y variada, pero es evidente que ha contribuido como complemento suficiente de glucosa derivada del azúcar para mantener a la población en actividad, pero estresada. Un mayor aumento de los derivados del azúcar, procedentes de cultígenos almidonosos en la dieta, parece haber involucrado un claro intercambio en Mórrope. Es evidente que esto ayudó a amortiguar los posibles resultados que van desde la desnutrición y hambre severos, pero claramente fue un factor sinérgico de los patrones observados por la elevada prevalencia de anemia, falta del crecimiento, depresión de fertilidad e infecciones.

\subsection{Las respuestas culturales a la Conquista}

Algunas poblaciones de nativos americanos, como los Guale de la Florida española, experimentaron una confluencia de condiciones poscontacto locales que llevaron a su extinción cultural (Larsen et al. 1992). Tal resultado podría ser fácilmente asumido por el muchik de Mórrope dada la evidencia bioarqueológica sobre la carga de mayor morbilidad y sufrimiento. Sin embargo, esta no es la forma como la historia se desarrolló en el valle de Lambayeque. En el contexto de aumento del estrés y las enfermedades, generaron complejas respuestas culturales.

Los objetivos españoles alrededor de la conquista y posterior colonización del Perú fueron todo lo contrario a la exterminación de las poblaciones nativas. Los pueblos originarios fueron necesarios 
para funcionar como fuente de mano de obra. Además, en el valle de Lambayeque en sí, el descenso demográfico no fue tan grave como en otras regiones y, hacia la década de 1620, alcanzó una disminución poblacional de aproximadamente el $40 \%$ antes de que la recuperación de la población comenzara (Cook 1981). A diferencia de estrechos valles costeros circunscritos, que fueron ideales para la transmisión rápida de enfermedades epidémicas, Lambayeque se extendió mucho más. En general, fue una región económicamente sana del Perú colonial. Todos los factores parecen ser factores de disuasión contra la extinción de la población. Entonces, ¿qué pasa con la extinción cultural?

En Mórrope colonial, la gente no sucumbió biológicamente a las presiones de la conquista y tampoco a las presiones culturales, aunque hay una clara evidencia de fricción cultural. En el manuscrito de Rubiños y Andrade (1782 [1936]), el pueblo muchik de Mórrope fue retratado como brutos, irracionales e ignorantes que se resistieron a la conversión. Algunos fueron bautizados, pero continuaron con las prácticas tradicionales como el chamanismo, por las que fueron perseguidos activamente. Figueroa e Idrogo (2003) caracterizan a los sacerdotes de Mórrope como un grupo particularmente opresivo y a menudo representado como exigente, sobre todo, con penas severas, incluido Modesto Rubińos, que, en 1780, tenía al curaca, indígenas y otros locales encarcelados en la sierra por la práctica de tradiciones locales. Los patrones de enterramiento observados en Mórrope parecen documentar los conflictos de formas que nunca las fuentes documentales habían retratado.

En el sentido más básico, probablemente, hubo dos tipos de agendas en conflicto en Mórrope colonial. Para los españoles, había una política expresa y la motivación religiosa para convertir a los nativos. Para los muchik, una agenda de línea de base fue la supervivencia (biológica y cultural), junto con el hecho de que, cuando se enfrentaban a cambios culturales impuestos desde el exterior, a menudo había una respuesta en contra. Los rituales basados en prácticas prehispánicas, como el cuerpo extendido en eje norte-sur, la reapertura de tumbas, la manipulación de cráneos y huesos largos, entierros primarios prolongados y el uso de pigmento rojo en la cara, se mezclaron con los ritos católicos. Una de las implicaciones más básicas es que el ritual prehispánico no fue exterminado en Mórrope, como podría suponerse a partir de amplias perspectivas etnohistóricas que detallan programas agresivos de extirpación en el Perú colonial. Sin embargo, se transformó. Los rituales nativos sobre la muerte se convirtieron en híbridos y se mezclaron con los elementos del nuevo orden. Esto denota la emergencia de una forma de sincretismo religioso en desarrollo, de un intercambio en varios niveles y la negociación como resultado de un conflicto entre dos entidades culturales que tenían sus propias agendas distintas (Wernke 2007a). Esto podría representar no solo la hibridación cultural que emerge de un intercambio dialéctico fluido y del entrelazamiento de las dos tradiciones, sino también de la hostilidad entre los grupos.

Los entierros son y han sido dominio de la resistencia o guerra ideológica, incluso durante los períodos de agitación cultural e inestabilidad (Bawden 2001, 2005). Al considerar la resistencia, es importante evitar las nociones deterministas, unidimensionales y superficiales. Del mismo modo, la detección de correlaciones arqueológicas de resistencia puede ser extremadamente difícil (Quilter 2010). Sin embargo, sabemos que la vida era difícil para el pueblo de Mórrope. Entonces, ¿podría el acto de crear y llevar a cabo rituales mortuorios híbridos implicar resistencia contra el orden establecido? ¿Se trata de cooptar por una idea o simbolismo ajeno? Además, ¿el aumento en el estrés fisiológico y el sufrimiento, observado empíricamente, podría proporcionar bases para hablar de resistencia cultural? En otras palabras, ¿el estrés podría proporcionar bases importantes para respuestas culturales a la conquista? En cualquier caso, el tema de la resistencia no es un desafío sencillo, pero los actos tienen su origen en los intentos creativos y dinámicos por comprender y dominar un mundo cambiante. «La resistencia y la protesta se producen junto a la reexaminación activa de los valores anteriores, junto con el desarrollo de nuevos conceptos sobre el mundo que, efectivamente, recibieron el aporte europeo, y que además son el producto de las mentes indígenas» (Graham 1998: 29).

Los rituales funerarios fueron híbridos en Mórrope por haber servido al propósito de la conservación de la identidad muchik cuando las concepciones locales del yo y el grupo se encontraban 
bajo significativa presión negativa. En efecto, los significados de los rituales precontacto en particular pueden haber cambiado de forma, lo que no es fácil de detectar al convertirse en parte de una práctica colonial nueva. Sin embargo, sus formas se mantuvieron inminentemente reconocibles por estar vinculadas a un origen local. La reproducción de las actividades y símbolos tradicionales (especialmente, los entierros secundarios que pueden interpretarse como una afirmación de la colectividad y cohesión grupal), ha sido incorporada a la memoria social y la ideología, mientras que la transmisión de una fuerza emocional estimula la construcción y mantenimiento de la identidad de grupo distinta de la de los colonos y el cristianismo. A diferencia de la noción de Kubler (1961: 32) de un «reemplazo total en materia simbólica» que siguió a la conquista, Mórrope adoptó un compromiso dinámico muy similar a lo visto a través de los indígenas de Perú después de una lucha de 200 años. Además, los agustinos fueron los primeros misioneros en Mórrope. En estos primeros días, la orden estuvo seguida de una mezcla entre católicos y gente de creencias andinas con una base común de lenguajes híbridos mutuamente inteligibles como forma de "persuasión» (Andrien 2001). Al momento de la aplicación doctrinal en Mórrope, la purga de prácticas arraigadas (a la que se alude como «errores» $\mathrm{y}$ «malos entendidos»), resultó difícil de superar (Rubiños y Andrade 1782 [1936]).

\section{Conclusiones}

La evaluación bioarqueológica inicial de la Costa Norte del Perú colonial indica una morbilidad indígena sin precedentes: la primera hipótesis es aceptada. Sin embargo, en las condiciones de estrés biológico crónico, la cultura indígena muchik no fue desaparecida: la segunda hipótesis es rechazada. Los intentos relativamente exitosos para mantener las tradiciones e identidades locales pueden haber sido parte de una constelación de respuestas indígenas para amortiguar las consecuencias negativas del colonialismo. Si bien puede ser fácil considerar esto en términos de hibridación cultural o sinergia, la interacción entre Europa y el ritual andino en Mórrope fue probablemente más compleja. Sostengo en detalle, en otra publicación (Klaus 2008, en prensa 1), que es un signo de etnogénesis, la creación de un nuevo tipo de identidad muchik en un momento de amplia discordia social y una amenaza externa que cambia los comportamientos culturales muchik que tuvieron un impacto en la estructura de su acervo genético.

Metodológicamente, este estudio tuvo como objetivo ilustrar la variedad de vínculos complementarios y vitales entre la biología humana y la arqueología funeraria. Tal vez, el mayor problema actual en el estudio de los restos humanos es la falta de síntesis entre el análisis de entierros y la bioarqueología. Este es un problema generalizado no solo en los estudios peruanos; también lo es dentro de la arqueología en general. Aquí, he dirigido la integración de datos funerarios con la biología del esqueleto para proporcionar una visión más holística de las cuestiones sociales, históricas y biológicas. Un contexto funerario realmente puede ser visto como la fuente más densa y rica con información de todo tipo de yacimiento arqueológico. De esta manera, el esqueleto humano y su enterramiento pueden ser vistos como un datum de la realidad cultural para entender las manifestaciones biológicas en relación con los estudios funerarios, los registros arqueológicos, ambientales e históricos (Gowland y Knusel 2006). Esto es especialmente importante para el futuro estudio del Perú colonial, y puede ayudar a estimular nuevas ideas y direcciones a medida que desarrollemos una comprensión científica más completa de la historia andina.

\section{Agradecimientos}

A la Fundación Wenner-Gren, la Fundación Tinker, y la Oficina de Asuntos Internacionales del Centro de Estudios Latinoamericanos y el Departamento de Antropología de la Universidad del Estado de Ohio, otorgadas a $\mathrm{H}$. Klaus y con las que generosamente se han financiado las investigaciones en Mórrope desde 2004 hasta 2006. Agradezco las numerosas contribuciones vitales 
de Rosabella Alvarez-Calderón, Víctor Curay, Carlos Elera, Julie Farnum, Gabriela Jakubowska, Cesar Maguińa, Emily Middleton, Analise Polsky, Raul Saaverda, Izumi Shimada, Marla Toyne, y Carlos Wester. Al Museo Nacional Sicán en Ferreñafe, que nos facilitó de manera esencial el espacio de laboratorio y logística. A Clark Larsen y Paul Sciulli quienes comentaron las versiones anteriores de varios elementos en este artículo.

\section{REFERENCIAS}

Alva, W.

2008 Las tumbas reales de Sipán, en: K. Makowski (ed.), Señores de los reinos de la luna, 266-279, Banco de Crédito, Lima.

Andrien, K.

2001 Andean worlds: Indigenous history, culture, and consciousness under Spanish rule, 1523-1825, University of New Mexico Press, Albuquerque.

Baker, B. J. y L. Kealhoffer (eds.)

1996 Bioarchaeology of native American adaptation in the Spanish borderlands, University Presses of Florida, Gainesville.

Bawden, G.

2001 The symbols of Late Moche social transformation, en: J. Pillsbury (ed.), Moche art and archaeology in ancient Peru, 285-305, Yale University Press, New Haven.

2005 Ethnogenesis at Galindo, Peru, en: R. Martin Reycraft (ed.), Us and them: Archaeology and ethnicity in the Andes, 12-33, Cotsen Institute of Archaeology, Los Angeles.

Beck, Lane Anderson (ed.)

1995 Regional Approaches to Mortuary Analysis, Plenum, New York.

Bodley, J. H.

1999 Victims of progress, Mayfield, Mountain View.

Bogin, B.

1999 Patterns of human growth, 2da ed., Cambridge University Press, Cambridge.

2001 The growth of humanity, Wiley-Liss, New York.

Bourget, Steve

2001 Rituals of Sacrifice: Its Practice at Huaca de la Luna and its Representation in Moche Iconography, en J. Pillsbury (ed.), Moche Art and Archaeology in Ancient Peru, National Gallery of Art, Washington, D.C.

Buikstra, J. E. y D. H. Ubelaker

1994. Standards for data collection from human skeletal remains, Arkansas Archaeological Survey Research Series No. 44, Fayetteville.

Buikstra, J. E., L. W. Konigsberg y J. Bullington

1986 Fertility and the development of agriculture in the prehistoric Midwest, American Antiquity 51: 528-546. https://doi.org/10.2307/281750

Cleland, Kate M. e Izumi Shimada

1998 Paleteada Potters: Technology, Production Sphere, and Sub-Culture in Ancient Peru, en Izumi Shimada (ed.), Andean Ceramics: Technology, Organization, and Approaches, 111-150, Museum Applied Science Center for Archaeology and University of Pennsylvania Museum of Archaeology and Anthropology, Philadelphia.

Cohen, M. N. y G. Crane-Kramer

2007 Appendix, en: M. N. Cohen y G. M.M. Crane-Kramer (eds.), Ancient health: Skeletal indicators of agricultural and economic intensification, 345-347, University of Florida Press, Gainesville.

Cohen, M. N., K. O'Connor, M. Danforth, K. Jacobi y C. Armstrong

1997 Archaeology and osteology of the Tipu site, en: S. L. Wittington y D. M. Reed (eds.), Bones of the Maya: Studies of ancient skeletons, 79-86, Smithsonian Institution Press, Washington, D.C. 
Collin Delavaud, C.

1984 Las regiones costeñas del Perú septentrional, Pontificia Universidad Católica del Perú, Lima.

Contreras, C. (ed.)

2009 Economía del periodo Colonial Temprano, Compendio de historia económica del Perú, tomo 2, Banco Central de Reserva del Perú/Instituto de Estudios Peruanos, Lima.

2010 Economía del Periodo Colonial Tardío, Compendio de historia económica del Perú, tomo 3, Banco Central de Reserva del Perú/Instituto de Estudios Peruanos, Lima.

Cook, N. D.

1981 Demographic collapse: Indian Peru, 1520-1620, Cambridge University Press, Cambridge. https://doi. org/10.1017/cbo9780511572715

Elera, C.

1997 Cupisnique y Salinar: Algunas reflexiones preliminares, en: E. Bonnier y H. Bischof (eds.), Prehispanic architecture and civilization in the Andes, 177-20, Reiss Museum, Manheim.

Ellison, P. T.

1994 Advances in human reproductive ecology, Annual Review of Anthropology 23: 225-75. https://doi. org/10.1146/annurev.anthro.23.1.255

Figueroa, G. y N. Idrogo

2004 Lambayeque en el Perú colonial, Cipdes, Chiclayo.

Goodman A. H. y J. C. Rose

1990 Assessment of physiological perturbations from dental enamel hypoplasias and associated histological structures, Yearbook of Physical Anthropology 33: 59-110.

Gowland, R. y C. Knüsel

2006 Introduction, en: R. Gowland y C. Knüsel (eds.), The social archaeology offunerary remains, ix-xiv, Oxbow Books, Cambridge.

Graubart, K. B.

2000 Weaving and the construction of a gender division of labor in Early Colonial Peru, American Indian Quarterly 24: 537-561. https://doi.org/10.1353/aiq.2000.0017

Graham, E.

1998 Mission archaeology, Annual Review of Anthropology 27: 25-62.

Haskell, N. H., R. D. Hall, V. J. Cervenka y M. A. Clark

1997 On the body: Insects' Life stage presence and their postmortem artifacts, en: W. D. Haglund y M. H. Sorg (eds.), Forensic taphonomy: The postmortem fate of human remains, 415-448, CRC Press, Boca Raton. https://doi.org/10.1201/9781439821923.ch27

Heyerdahl, T., D. H. Sandweiss, A. Narváez y L. Millones

1996 Túcume, Banco de Crédito del Perú, Lima.

Hillson, $S$.

2008 The current state of dental decay, en: J. D. Irish y G. C Nelson (eds.), Technique and application in dental anthropology, 11-135, Cambridge University Press, Cambridge. https://doi.org/10.1017/ cbo9780511542442.006

Huss-Ashmore, R., A. H. Goodman y G. J. Armelagos

1982 Nutritional inference from paleopathology, en: M. B. Schiffer (ed.), Advances in archaeological method and theory, 395-474, Academic Press, New York.

Jakes, M.

2000 Building the Bases for Paleodemographic Analysis: Adult Age Determination, en M. Anne Katzenberg y Shelley R. Saunders (eds.), Biological Anthropology of the Human Skeleton, 417-466, Wiley-Liss, Nueva York.

Jurmain, R.

1999 Stories from the skeleton: Behavioral reconstruction in human osteology, Gordon and Breach, Amsterdam. 
Keith, R. G.

1986 Conquest and Agrarian Change: The Emergence of the Hacienda System on the Peruvian Coast, Harvard University Press, Cambridge.

Kent, S.

1986 The influence of sedentism and aggregation on porotic hyperostosis and anemia: A case study, Man 21: 605-636.

Klaus, H. D.

2008 Out of light came darkness: Bioarchaeology of mortuary ritual, health, and ethnogenesis in the Lambayeque Valley, north coast of Peru (A.D. 900-1750), tesis de doctorado, Departamento de Antropología, The Ohio State University, Columbus.

2013 Hybrid cultures... and hybrid peoples: Bioarchaeology of genetic change, religious architecture, and burial ritual in the colonial Andes, en: J. Card (ed.), Hybrid material culture: The archaeology of syncretism and ethnogenesis, 207-238, Center for Archaeological Investigations, Southern Illinois University, Carbondale.

2014 La población Muchik de la cultura Sicán Medio: una primera aproximación a un sustrato cultural prehispánico tardío del valle de Lambayeque, en: I. Shimada (ed.), Cultura Sicán: esplendor preincaico de la costa norte, 235-257, Fondo Editorial del Congreso del Perú, Lima.

Klaus, H. D. y M. E. Tam

2009a Surviving Contact: Biological Transformation, Burial, and Ethnogenesis in the Colonial Lambayeque Valley, North Coast Peru, en: K. J. Knudson y C. M. Stojanowski (eds.), Bioarchaeology and identity in the Americas, 126-152, University Press of Florida, Gainesville. https://doi.org/10.5744/florida/ 9780813036786.003 .0006

2009 b Contact in the Andes: Bioarchaeology of systemic stress in colonial Mórrope, Peru. American Journal of Physical Anthropology 138: 356-368. https://doi.org/10.1002/ajpa.20944

2010 Oral health and the postcontact adaptive transition: A contextual reconstruction of diet in Mórrope, Peru, American Journal of Physical Anthropology 141: 594-609. https://doi.org/10.1002/ajpa.21179

2014 Requiem aeternam? Archaeothanatology of mortuary ritual in colonial Mórrope, north coast of Peru, en: I. Shimada y J. Fitzsimmons (eds.), Living with the dead in the Andes, 267-303, University of Arizona Press, Tucson.

Klaus, H. D., A. K. Wilbur, D. H. Temple, J. E. Buikstra, A. C. Stone, M. Fernández, C. Wester y M. E. Tam 2010 Tuberculosis on the north coast of Peru: Skeletal and molecular paleopathology of late pre-Hispanic and postcontact mycobacterial disease, Journal of Archaeological Science 37: 2587-2587. https://doi. org/10.1016/j.jas.2010.05.019

Klaus, H. D., I. Shimada, K. Shinoda y S. Muno

2014 Consecuencias de la estructura social de la cultura Sicán Medio sobre la salud y la variación biocultural: Perspectivas de los rituales funerarios, biología esquelética, y las estructuras genéticas, en: J. C. Fernando Alvarado y C. Wester La Torre (eds.), Cultura Lambayeque en el contexto de la costa norte del Perú, 215-242, EMDECOSEGE, Chiclayo.

Kubler, G.

1961 On the colonial extinction of the motifs of pre-Columbian art, en: S. K. Lothrop (ed.), Essays in preColumbian art and archaeology, 14-34, Harvard University Press, Cambridge.

Larsen, C. S.

2001 Bioarchaeology of Spanish Florida, en: C. S. Larsen (ed.), Bioarchaeology of Spanish Florida: The impact of colonialism, 22-51, University Press of Florida, Gainesville.

2015 Bioarchaeology: Interpreting behavior from the human skeleton, 2da ed., Cambridge University Press, Cambridge.

Larsen, C. S., y G. R Milner (ed.)

1994 In the wake of contact: Biological responses to conquest, Wiley-Liss, New York.

Larsen, C. S., C. B. Ruff, M. M. Schoeninger y Dale L. Hutchinson

1992 Population decline and extinction in La Florida, en: J. W. Verano y D. H. Ubelaker (eds.), Disease and demography in the Americas, 25-39, Smithsonian Institution Press, Washington, D.C. 


\section{Lovejoy, C. O., R. S. Meindl, R. Mensforth y T. J. Barton}

1985 Multifactorial determination of skeletal age at death: A method and blind tests of its accuracy, American Journal of Physical Anthropology 68:1-14. https://doi.org/10.1002/ajpa.1330680102

Lovejoy C. O., K. F. Russell y M. L. Harrison

1990 Long bone growth velocity in the Libben population, American Journal of Human Biology 2: 533-541. https://doi.org/10.1002/ajhb.1310020509

Lukacs, J. R.

2007 Dental trauma and antemortem tooth loss in prehistoric Canary Islanders: Prevalence and contributing factors, International Journal of Osteoarchaeolgy 17: 157-173. https://doi.org/10.1002/oa.864

Martorell, R.

1989 Body size, adaptation and function, Food Research Institute, Stanford University, Stanford.

Martorell R, C. Yarborough, A. Lechtig, J. Habicht, R. E. Klein

1975 Diarroheal diseases and growth retardation in preschool Guatemalan children, American Journal of Physical Anthropology 43: 341-352. https://doi.org/10.1002/ajpa.1330430307

Merbs, C. F.

1983 Patterns of activity-induced pathology in a Canadian Inuit population, Archaeological Survey of Canada, National Museum of Man, Mercury Series, No. 119, National Museums of Canada, Ottawa.

Murphy, M. S., E. Goyochea y G. Cock

2010a Resistance, persistence and accomodation at Puruchucho-Huaquerones, en: M. Liebmann y M. S. Murphy (eds.), Enduring conquests: Rethinking the archaeology of reistance to Spanish colonialism in the Americas, 57-76, School for Advanced Research Press, Santa Fe.

Murphy, M. S., C. Gaither, E. Goyochea, J. W. Verano y G. Cock

$2010 \mathrm{~b}$ Violence and weapons-related trauma at Puruchucho-Huaquerones, Peru, American Journal of Physical Anthropology 142: 636-649. https://doi.org/10.1002/ajpa.21291

Netherly, P. J.

1984 The management of late Andean irrigation systems on the North Coast of Peru, American Antiquity 49: 227-254. https://doi.org/10.2307/280017

Pearson, O. M., y J. E. Buikstra

2006 Behavior and the bones, en: J. E. Buikstra y L. A. Beck (eds.), Bioarchaeology: The contextual analysis of human remains, 207-225, Elsevier, Amsterdam.

Peralta, V.

1998 Caminantes de desierto, arrieros y comerciantes indígenas en Lambayeque, Siglo XVIII, en: S. O'Phelan Godoy (ed.), El norte en la historia regional, 143-157, CIPCA/Instituto Francés de Estudios Andinos, Lima. https://doi.org/10.4000/books.ifea.3299

Quilter, J.

2007 El Brujo a inicios de la colonia/El Brujo at the beginning of the Colonial Period, en: E. Mujica (ed.), El Brujo: Huaca Cao, centro ceremonial Moche en el valle de Chicama/Huaca Cao, Moche ceremonial enter in the Chicama Valley, 287-308, Fundación Wise, Lima.

2010 Cultural encounters at Magdalena de Cao Viejo in the Early Colonial Period, en: M. Liebmann y M. S. Murphy (eds.), Enduring conquests: rethinking the archaeology of resistance to Spanish Colonialism in the Americas, 103-125, School for Advanced Research Press, Santa Fe.

Ramírez, S. R.

1996 The world upside down: Cross-cultural contact and conflict in sixteenth-century Peru, Stanford University Press, Stanford.

Ramos, G.

2010 Muerte y conversión en Los Andes: Lima y Cuzco, 1532-1670, Instituto de Estudios Peruanos, Lima. https://doi.org/10.4000/books.ifea.6263

Rubińos y Andrade, D. J. M.

1782 Noticia previa por el Liz. D Justo Modesto Rubińos, y Andrade, cura de Mórrope año de 1782, Revista

[1936] Historica 10: 291-363. 
SAS Institute, Inc.

2003 SAS version 9.1, SAS Institute Inc., Cary.

Sattenspiel, L. y H. H. Harpending

1983 Stable populations and skeletal age, American Antiquity 48: 489-498. https://doi.org/10.2307/280557

Scheuer, L. y S. Black

2000 Developmental juvenile osteology, Elsevier, Amsterdam. https://doi.org/10.1016/b978-0-12-624000-9. x $5000-\mathrm{x}$

Shimada, I.

1994 Pampa Grande and Mochica culture, University of Texas Press, Austin.

1995 Cultura Sicán: Dios, riqueza y poder en la Costa Norte del Perú, Edubanco, Lima.

Shimada, I., K. Shinoda, J. F. Farnum, R. Corruccini y H. Watanabe

2004 An integrated analysis of pre-Hispanic mortuary patterns: A Middle Sicán case study, Current Anthropology 45: 369-402. https://doi.org/10.1086/382249

Shimada, I., H. D. Klaus, R. Segura y G. Matsumoto

2014 Living with the Dead: Conception and Treatment of the Dead on the Central and North Coast of Peru, en: I. Shimada y J. Fitzsimmons (eds.), Between the living and the dead: Cross-disciplinary and diachronic perspectives, vol. 1: Andes, University of Arizona Press, Tucson.

Shimada, M. e I. Shimada

1985 Prehistoric llama breeding and herding on the north coast of Peru, American Antiquity 50: 3-26. https:// doi.org/10.2307/280631

Stern, S. J.

1982 Peru's Indian peoples and the challenge of Spanish conquest: Huamanga to 1640, University of Wisconsin Press, Madison.

Sokal, R. y F. J. Rohlf

1995 Biometry: The principles and practice of statistics in biological research, W.H. Freeman, New York.

Tiesler, V., P. Zabala y A. Cucina (eds.)

2010 Natives, Europeans, and Africans in colonial Campeche: History and archaeology, University Press of Florida, Gainesville. https://doi.org/10.5744/florida/9780813034928.001.0001

Ubelaker, D. H., y Linda A. Newson

2002 Patterns of health and nutrition in prehistoric and historic Ecuador, en: R. H. Steckel y J. C. Rose (eds.), The backbone of history: Health and nutrition in the western hemisphere, 343-375, Cambridge University Press, Cambridge. https://doi.org/10.1017/cbo9780511549953.016

Verano J. W. y D. H. Ubelaker (eds.)

1992 Disease and demography in the Americas, Smithsonian Institution Press, Washington, D.C.

Waldron, $\mathrm{T}$.

1994 Counting the dead: The epidemiology of skeletal populations, John Wiley and Sons, Chinchester.

Walker, P. L.

1986 Porotic Hyperostosis in a Marine-Dependent California Indian Population, American Journal of Physical Anthropology 69: 345-354

Walker, P. L., R. R. Bathurst, R. Richman, T. Gjerdrum y V. A. Andrushko

2009 The causes of porotic hyperostosis and cribra orbitalia: A reappraisal of the iron-deficiency-anemia hypothesis, American Journal of Physical Anthropology 139: 109-125. https://doi.org/10.1002/ajpa.21031

Wernke, S. A

2007a Analogy or erasure? Dialectics of religious transformation in the early doctrinas of the Colca Valley, Peru, International Journal of Historical Archaeology 11:152-182. https://doi.org/10.1007/s10761-007-0027-5

2007b Excavating between the lines: Textual silences and missionary archaeology in the Colca Valley, Peru, ponencia presentadoa en el 73va reunion de la Sociedad Americana de Arqueología, Vancouver.

2010 Convergences: Producing early colonial hybridity at a doctrina in highland Peru, en: M. Liebmann y M. S. Murphy (eds.), Enduring conquests: Rethinking the archaeology of resistance to Spanish colonialism in the Americas,77-101, School for Advanced Research Press, Santa Fe. 